\title{
A review on chemical constituents and pharmacological activities of Coriandrum sativum
}

\author{
Prof Dr Ali Esmail Al-Snafi \\ Department of Pharmacology, College of Medicine, Thi qar University, Iraq
}

\begin{abstract}
The phytochemical screening of Coriandrum sativum showed that it contained essential oil, tannins, terpenoids, reducing sugars, alkaloids, phenolics, flavonoids, fatty acids, sterols and glycosides. It also contained high nutritional values including proteins, oils, carbohydrates, fibers and wide range of minerals, trace elements and vitamins. The previous pharmacological studies revealed that it possessed anxiolytic, antidepressant, sedative-hypnotic, anticonvulsant, memory enhancement, improvement of orofacial dyskinesia, neuroprotective, antibacterial, antifungal, anthelmintic, insecticidal, antioxidant, cardiovascular, hypolipidemic, anti-inflammatory, analgesic, antidiabetic, mutagenic, antimutagenic, anticancer, gastrointestinal, deodorizing, dermatological, diuretic, reproductive, hepatoprotective, detoxification and many other pharmacological effects. The current review was designed to give an overview on the chemical constituents and pharmacological effects of Coriandrum sativum.
\end{abstract}

Keywords: constituents, pharmacology, Coriandrum sativum.

\section{INTRODUCTION}

Herbal medicine is the oldest form of medicine known to mankind. It was the mainstay of many early civilizations and still the most widely practiced form of medicine in the world today. Plants generally produce many secondary metabolites which are bio-synthetically derived from primary metabolites and constitute an important source of many pharmaceutical drugs [1-30]. The phytochemical screening of Coriandrum sativum showed that it contained essential oil, tannins, terpenoids, reducing sugars, alkaloids, phenolics, flavonoids, fatty acids, sterols and glycosides. It also contained high nutritional values including proteins, oils, carbohydrates, fibers and wide range of minerals, trace elements and vitamins. The previous pharmacological studies revealed that it possessed anxiolytic, antidepressant, sedative-hypnotic, anticonvulsant, memory enhancement, improvement of orofacial dyskinesia, neuroprotective, antibacterial, antifungal, anthelmintic, insecticidal, antioxidant, cardiovascular, hypolipidemic, anti-inflammatory, analgesic, antidiabetic, mutagenic, antimutagenic, anticancer, gastrointestinal, deodorizing, dermatological, diuretic, reproductive, hepatoprotective, detoxification and many other pharmacological effects. The current review gives an overview on the chemical constituents and pharmacological effects of Coriandrum sativum.

Plant profile:

\section{SYNONYMS}

Bifora loureiroi Kostel., Coriandropsis syriaca H. Wolff, Coriandrum globosum Salisb., Coriandrum majus Gouan, Selinum coriandrum Krause [31].

\section{III- TAXONOMIC CLASSIFICATION}

Kingdom: Plantae; Subkingdom: Tracheobionta; Superdivision: Spermatophyta; Division: Magnoliophyta; Class: Magnoliopsida; Subclass: Rosidae; Order: Apiales; Family: Apiaceae; Genus: Coriandrum L.; Species: Coriandrum sativum L [32-33].

\section{COMMON NAMES}

Arabic: kuzbara, kuzbura; Chinese: yuan sui, hu sui; English: coriander, cilantro, collender, Chinese parsley; French: coriander, coriandre cultivé; German: Koriander, Wanzendill, Schwindelkorn; Greek: koriannon, korion; Hindi: dhania, dhanya; Italian: coriandolo, coriandro; Japanese: koendoro; Portuguese: coentro, coriandro; Sanskrit: dhanayaka, kusthumbari; Spanish: coriandro, cilantro, cilandrio, cilantro; Swedish: coriander [34-35].

\section{DISTRIBUTION}

Coriandrum sativum probably originated from Eastern Mediterranean and it was spread as a spice plant to India, China, Russia, Central Europe, and Morocco, and has been cultivated since human antiquity [36]. However, now it was distributed in Europe (Denmark, Finland, Ireland, Norway, Sweden, UK, Austria, Belgium, Czechoslovakia, Germany, Hungary, the Netherlands, Poland, Switzerland, Belarus, Estonia, Latvia, 
Lithuania, Moldova, Ukraine, Albania, Bulgaria, Greece, Italy, Romania, Yugoslavia, France, Portugal and Spain), Northern Africa (Algeria, Morocco, Tunisia and Ethiopia), Asia (Afghanistan, Iran, Iraq, Palestine, Jordan, Lebanon, Syria, Turkey, Armenia, Azerbaijan, Georgia, southern Russia, Kazakhstan, Kyrgyzstan, Tajikistan, Turkmenistan, Uzbekistan, China, India and Pakistan) [35, 37].

\section{DESCRIPTION}

It is an upright and short-lived herbaceous plant usually growing 1-2 $\mathrm{m}$. Stems and leaves: The branched stems are hairless (i.e. glabrous), mostly hollow, and have fine lengthwise (i.e. longitudinal) grooves. They are pale green in colour but covered in distinctive purplish or pinkish blotches. The alternately arranged leaves are borne on long hollow leaf stalks (i.e. petioles) that tend to sheath the stem at their bases. They are deeply divided (i.e. bi-pinnatisect), with toothed (serrate) segments, and are ferny in appearance. These leaves (up to $50 \mathrm{~cm}$ long and $40 \mathrm{~cm}$ wide, but more commonly $12-25 \mathrm{~cm}$ long) are hairless (glabrous). The upper leaf surfaces are dark green in colour, while their undersides are a paler green or greyish-green. The stems and leaves give off a strong odour when crushed or damaged. Flowers and Fruit: The white flowers are borne in large numbers in dense flat-topped clusters at the tips of the branches (in terminal compound umbels). Individual flowers are small (2-4 mm across), have five incurved petals and five stamens, and are borne on stalks (pedicels) up to $5 \mathrm{~cm}$ long. Many (about 15) of these stalks (pedicels) radiate from the same point and form a small cluster of flowers (an umbel), with several (6-20) of these smaller clusters (often called rays) being grouped together into a much larger cluster (a compound umbel) that is subtended by several small leafy bracts (about $5 \mathrm{~mm}$ long). Flowering occurs mostly during spring and summer. The fruit turns from green to greyish-brown in colour as it matures and resembles a capsule. It actually consists of two one-seeded structures (mericarps) that readily split apart when the fruit is fully mature. Each of these (seeds), 2-4 mm long, hairless (glabrous), but has five prominent yellowish-coloured ribs. There are many varieties of Coriandrum sativum which differ in the fruit size and oil yield [36-39].

\section{TRADITIONAL USES:}

The use of coriander dated back to around $1550 \mathrm{BC}$, and it was one of the oldest spice crops in the world. Medicinally, it was used as stimulant, aromatic and carminative. The powdered fruit, fluid extract and oil are chiefly used medicinally as flavouring to disguise the taste of active purgatives and correct their griping tendencies. The whole or ground seed (fruit) was an ingredient of pickling spices, also used to flavor various commercial foods, particularly, to prepare some instant soups and dishes, in many cakes, breads and other pastries, alcoholic beverages, frozen dairy desserts, candy, and puddings. The fruit essential oil was a common ingredient in creams, detergents, surfactants, emulsifiers, lotions, and perfumes [40].

However, seeds were applied locally to alleviate swelling and pains. Paste of green coriander were used for headache. Externally, powdered green coriander was used to alleviate burning sensation and pain in diseases like inflammation caused by erysipelas and lymphadenopathy. Decoction of green coriander was used in stomatitis. Nasal drops of green coriander act as a haemostat and thus stop bleeding in epistaxis. Juice or decoction of green coriander was used in conjunctivitis. The seeds were included in many prescriptions as carminative and for the treatment of fever, diarrhoea, vomiting and indigestion. Coriander was used internally as tonics. It was also used for syncope and memory loss. Fresh juice of leaves was used as gargle in sore throat and stomatitis. Paste of leaves were locally applied for swellings and boils and were applied over forehead and temples for headache [41-44].

Parts used: Fruit and fresh leaves [40-44].

Physicochemical characteristics:

Total ash: not more than 6 per cent, acid insoluble ash: not more than 1.5 per cent, water-soluble extractive: not more than 19 per cent, alcohol soluble extractive: not more than 10 per cent and volatile oil: not less than $0.3 \%$ $\mathrm{v} / \mathrm{w}[45]$.

\section{CHEMICAL CONSTITUENTS:}

kcal, protein 21.93 and $12.37 \mathrm{~g}$, total lipid (fat) 4.78 and $17.77 \mathrm{~g}$, carbohydrate 52.10 and $54.99 \mathrm{~g}$, fiber 10.40 and $41.9 \mathrm{~g}$, calcium 1246 and $709 \mathrm{mg}$, iron 42.46 and $16.32 \mathrm{mg}$, phosphorus 481 and $409 \mathrm{mg}$, magnesium 694 and $330 \mathrm{mg}$, potassium 4466 and $1267 \mathrm{mg}$, sodium 211 and $35 \mathrm{mg}$, zinc 4.72 and $4.70 \mathrm{mg}$, vitamin C 566.7 and $21 \mathrm{mg}$, thiamin 1.252 and $0.239 \mathrm{mg}$, riboflavin 1.500 and $0.290 \mathrm{mg}$, niacin 10.707 and $2.130 \mathrm{mg}$, vitamin B-120.00 and $0.00 \mu \mathrm{g}$, vitamin A, RAE 293 and $0.00 \mu \mathrm{g}$, vitamin A, IU $5850 \mathrm{IU}$ and $0 \mathrm{IU}$ and vitamin D (D2 + D3) 0.00 and $0.00 \mu \mathrm{g}$, respectively [40, 46-47].

The phytochemical screening of plant showed the presence of essential oil, tannins, terpenoids, reducing sugars, alkaloids, phenolics, flavonoids, fatty acids, sterols and glycosides [48-50]. 
The most important constituents of coriander fruits were the essential oil and fatty oil. The essential oil content of dried coriander fruits varies between 0.03 and $2.6 \%$, while the fatty oil content varies between 9.9 and $27.7 \%$ [40].

The variations in the oil constituents of Coriandrum sativum leaves and seeds could be attributed to the variations in the cultivar and not due to geographic divergence and ecological conditions. However, the compounds isolated from Coriander essential oil were included: Monoterpene hydrocarbons ( $p$-cymene, camphene, $\Delta$-3-carene, limonene (dipentene), myrcene, cis- and trans-ocimene, $\alpha$-phellandrene, $\beta$-phellandrene, $\alpha$ - pinene, $\beta$-pinene, sabinene, $\alpha$-terpinene, $\gamma$-terpinene, terpinolene, $\alpha$-thujene); Monoterpene oxides and Carbonyls (Camphor, 1,8- cineole, linalol oxide, carvone, geranial); Monoterpene alcohols (Borneol, citronellol, geraniol, linalool, nerol, $\alpha$-terpineol, 4-terpinenol); Monoterpene Esters (Bornyl acetate, geranyl acetate, linalyl acetate, $\alpha$-terpinyl acetate); Sesquiterpenes ( $\beta$-Caryophyllene, caryophellene oxide, elemol, nerolidol); Phenols (Anethole, myristicin, thymol); Aliphatic hydrocarbons (Heptadecane, octadecane); Aliphatic alcohols (Decanol, dodecanol); Aliphatic aldehydes (Octanal, nonanal, decanal, undecanal, dodecanal, tridecanal, tetradecanal, 3 octenal, 2-decenal, 5-decenal, 8-methyl-2-nonenal, 8- methyl-5-nonenal, 6-undecenal, 2-dodecenal, 7dodecenal, 2-tridecenal, 8- tridecenal, 9-tetradecenal, 10-pentadecenal, 3,6-undecadienal, 5,8-tridecadienal) and Miscellaneous compounds: Acetic acid, $\alpha$-pdimethyl styrene) [51-52].

The analysis of the essential oil conducted by gas chromatography-mass spectroscopy, revealed 33 components, representing $99.99 \%$ of the total oil from the seeds of coriander. The major components were linalool $(55.09 \%)$, $\alpha$-pinene (7.49\%), 2,6-Octadien-1-ol, 3,7-dimethyl-, acetate, (E)- (5.70\%), geraniol (4.83\%), 3-Cyclohexene-1methanol, $\alpha, \alpha, 4$-trimethyl- (4.72\%), hexadecanoic acid (2.65\%), tetradecanoic acid (2.49\%), 2- $\alpha$-pinene $(2.39 \%)$, citronellyl acetate (1.77\%), and undecanal (1.29\%) [53-54].

Sudanese Coriandrum sativum oils contained seventy eight compounds with sabinene (17.63\%), camphor $(15.5 \%)$, cis-beta-ocimene $(10.11 \%)$, trans-beta-ocimene $(5.64 \%)$, alpha pinene $(4.69 \%)$ and norboreneolacetate $(4.09 \%)$ as the main constituents [55].

The essential oils obtained from the coriander fruits, from Iran, by hydrodistillation (HD) and Microwaveassisted hydrodistillation (MAHD) then, the oils were analyzed by GC and GC-MS. The results indicated that the HD and MAHD isolated essential oils (EO) were dominated by monoterpenoids such as linalool, geranyl acetate and $\gamma$-terpinene. The major compound in both EO was linalool, its amount in HD and MAHD was $63 \%$ and $66 \%$, respectively. The total amount of monoterpenes hydrocarbons isolated by HD was differ significantly with the amount isolated by MAHD (12.56 \% compare to $1.82 \%)$ [56].

Coriander (Coriandrum sativum L.) seeds, from Germany, were extracted with chloroform/methanol (2:1, v/v) and the amount of total lipid was $28.4 \%$ of seed weight. The major fatty acid was petroselinic acid $(65.7 \%$ of the total fatty acid methyl esters) followed by linoleic acid, palmitoleic acid, arachidicacid, $\gamma$-linolenic acid, linolenic acid, gadoleic acid, cetoleic acid and docosahexanoic acid. Chromatographic analysis yielded 93.0\% neutral lipids, $4.14 \%$ glycolipids, and $1.57 \%$ phospholipids. Six triacylglycerol molecularspecies were detected but one component (C54:3) corresponding to tripetroselinin, and/or dipetroselinoyloleoyl glycerol comprised more than $50 \%$ of the totaltriacylglycerols. Sterol content was estimated to be at ahigh level (5186 $\mu \mathrm{g} / \mathrm{g}$ oil). Stigmasterol, $\beta$-sitosterol, $\Delta 5$-avenasterol, and campesterol were found to be the sterol markers. The major phospholipid subclasses were phosphatidylcholine followed by phosphatidylethanolamine, phosphatidy-linositol and phosphatidylserine [57].

The leaves and stems of Korean Coriandrum sativum were extracted and the essential oil composition were studied. Thirty-nine components representing $99.62 \%$ of the total oil were identified from the leaves. The major components were cyclododecanol $(23.11 \%)$, tetradecanal (17.86\%), 2-dodecenal (9.93\%), 1-decanol (7.24\%), 13-tetradecenal (6.85\%), 1-dodecanol (6.54\%), dodecanal (5.16\%), 1-undecanol (2.28\%), and decanal (2.33\%). On the other hand, thirty-eight components representing $98.46 \%$ of the total oil were identified from the stems of the coriander. The major components were phytol $(61.86 \%), 15$ - ethyltricyclo[6.5.2(13,14),0(7,15)]-pentadeca1,3,5,7,9,11,13-heptene (7.01\%), dodecanal (3.18\%), and 1-dodecanol (2.47\%) [58].

The leaf oil of Coriandrum sativum from Bangladesh contained 44 compounds mostly of aromatic acids, the major were 2-decenoic acid (30.82\%), E-11-tetradecenoic acid (13.4\%), capric acid (12.7\%), undecyl alcohol $(6.4 \%)$ and tridecanoic acid (5.5\%). Other major constituents in the leaf oil were undecanoic acid (2.13\%), 2-dodecanal (1.32\%), 2-undecenal (3.87\%), cyclododecane (2.45\%), decamethylene glycol $(1.15 \%)$, decanal $(1.35 \%)$ and dodecanoic acid (2.63\%). The seed oil contains 53 compounds of which the major compounds are linalool (37.65\%), geranyl acetate (17.57\%) and $\gamma$-terpinene $(14.42 \%)$. Other major compounds in the fruit oil are $\beta$ - pinene $(1.82 \%)$, m-cymene $(1.27 \%)$, citronellal $(1.96 \%)$, citronellol $(1.31 \%)$, citral $(1.36 \%)$, geraniol $(1.87 \%)$, citronellyl acetate $(1.36 \%), \alpha$-cedrene $(3.87 \%)$, and $\alpha$ - farnesene $(1.22 \%)$ and $\beta$-sesquiphellandrene $(1.56 \%)$. The seed oil contained 53 compounds, the major compounds were linalool (37.7\%), geranyl acetate $(17.6 \%)$ and $\gamma$-terpinene $(14.4 \%)$. However, the components isolated from seeds oil and their percentage were: $\gamma$-Terpinene 14.42, Camphene 0.14, E-Verbenol 0.27, Sabinene 0.23, $\beta$-Pinene 1.82, 2 Oxabicyclo[2.2.2]0ctan-6-1,1,2,3-trimethyl 0.02, $\beta$-Myrcene 0.55, Cyclooctanol 0.02, $\alpha$-Thujene 0.04, m- 
Cymene 1.27, Limonene 0.40, E-Ocimene 0.05, Z-Ocimene 0.04, Lilac alcohol 0.11, $\alpha$-Terpinene 0.04, ZVerbenol 0.11, Linalool 37.65, Isothujol 0.04, $\alpha$-Campholenal 0.22, Citronellal 1.96, Umbellulone 0.11, Borneol 0.32, 4-Terpineol 0.06, Terpinyl acetate 0.31, Decanal 0.14, Z-verbenone 0.10, Citronellol 1.31, Citral 1.36, Geraniol 1.87, Eugenol 0.90, Carveol 0.15, Undecanal 0.58, Methyl geranate 0.17, Myrtenyl acetate 0.43, Citronellyl acetate 1.36, Geranyl acetate 17.57, Z-myrtenyl acetate 0.10, $\beta$-Elemene 0.06, Dodecenal 0.15, Caryophyllene 0.33, $\beta$-Farnesene 0.07, 2-Dodecenal 0.18, Curcumene 0.98, $\alpha$-Cubebene $0.13, \alpha$-Cedrene 3.87, $\alpha$-Farnesene 1.22, $\beta$-Bisabolene 0.80, $\beta$-Sesquiphellandrene 1.56, E-Nerolidol 0.13, Artumerone 0.04, 8-Hexadecenal, 14-methyl-, (Z) 0.22, $\alpha$-Bisabolol 0.15 and n-Hexadecanoic acid 0.08 [59].

Many isocoumarins were isolated from the aerial parts of Coriandrum sativum, including coriandrone A, coriandrone $\mathrm{B}$, isocoumarins, coriandrin and dihydrocoriandrin [60].

Caffeic acid, protocatechinic acid, and glycitin were characterized as the major polyphenolics of coriander aerial parts [61]. However, Rajeshwari and Andallu found that the ethanolic extract of coriander seeds contained many flavonoids including caffeic acid, chlorogenic, quercetin and rutin [62]. However, the total polyphenolic content of the seeds was found to be 12.2 gallic acid equivalents (GAE)/g while total flavanoid content was found to be 12.6 quercetin equivalents/g [63].

The amount of flavonoids in $70 \%$ ethanol extract was found to be $44.5 \mu \mathrm{g}$ and that of the total phenols was $133.74 \mu \mathrm{g}$ gallic acid equivalents per $\mathrm{mg}$ of the hydro-alcohol extract of Coriandrum sativum leaves [64].

Central nervous effects:

IX.PHARMACOLOGICAL EFFECTS

\section{Anxiolytic effect:}

The anxiolytic effect of aqueous extract $(50,100,200 \mathrm{mg} / \mathrm{kg}$, ip) was examined in male albino mice using elevated plus- maze as an animal model of anxiety. In the elevated plus-maze, aqueous extract at 200 $\mathrm{mg} / \mathrm{kg}$ showed an anxiolytic effect by increasing the time spent on open arms and the percentage of open arm entries, compared to control group [65].

The anxiolytic effect of Coriandrum sativum (CS) aqueous extract was evaluated in mice. The antianxiety effect was assessed by elevated plus maze (EPM). In EPM, 50, 100, and $200 \mathrm{mg} / \mathrm{kg}$ of CS were significantly $(\mathrm{P}<0.001)$ increases the number of entries in open arms compared to control. The time spent in open arms also increased in all the doses of CS extract significantly [66].

The anti-anxiety activity of hydroalcoholic extract of Coriandrum sativum was studied using different animal models (elevated plus maze, open field test, light and dark test and social interaction test) of anxiety in mice. Diazepam $(0.5 \mathrm{mg} / \mathrm{kg})$ was used as astandard drug and hydroalcoholic extract of Coriandrum sativum fruit was used in dose of $(50,100$ and $200 \mathrm{mg} / \mathrm{kg})$ to study the antianxiety effect. Results revealed that the extract of Coriandrum sativum at 100 and $200 \mathrm{mg} / \mathrm{kg}$ dose produced anti-anxiety effects almost similar to diazepam, while, at $50 \mathrm{mg} / \mathrm{kg}$ dose, it did not produce anti-anxiety activity in all models [67].

The anxiolytic effect of the aqueous extract of Coriandrum sativum seed and its effect on spontaneous activity and neuromuscular coordination were evaluated in mice. The anxiolytic effect of aqueous extract $(10,25,50,100 \mathrm{mg} / \mathrm{kg}$, ip) was examined in male albino mice using elevated plus-maze as an animal model of anxiety. The effects of the extract on spontaneous activity and neuromuscular coordination were assessed using Animex Activity Meter and rotarod. In the elevated plus-maze, $100 \mathrm{mg} / \mathrm{kg}$ of the aqueous extract showed an anxiolytic effect by increasing the time spent on open arms and the percentage of open arm entries, compared to control group. Aqueous extract at 50,100 and $500 \mathrm{mg} / \mathrm{kg}$ significantly reduced spontaneous activity and neuromuscular coordination, compared to control group [68-69].

The effect of the hydroalcoholic extract of Coriandrum sativum leaves on the exploratory behaviour pattern and locomotor activity was investigated in mice. Elevated plus maze (EPM) and open field test (OFT) were used to assess the anxiolytic activity of the extracts. Diazepam $(1 \mathrm{mg} / \mathrm{kg})$ was used as standard anxiolytic agent. The 200 and $400 \mathrm{mg} / \mathrm{kg}$ body weight of the crude dried extract and diazepam produced highly significant $(\mathrm{P}<0.01)$ anxiolytic effects, in a dose-dependent manner, by increasing the time spent on, and the number of entries into the open arms of the EPM and by an increase in the locomotion by mice in the OFT. However, in lower doses the extract did not affect the locomotor activity [70].

The effects of fresh Coriandrum sativum leaves (CSL) on cognitive functions, total serum cholesterol levels and brain cholinesterase activity was investigated in mice. CSL $(5,10$ and $15 \%$ w/w of diet) was fed orally with a specially prepared diet, for 45 days consecutively to mice. Elevated plus-maze and passive avoidance apparatus were used as the exteroceptive behavioral models for testing memory. Diazepam, scopolamine and ageing-induced amnesia were used as the interoceptive behavioral models. CSL (5, 10 and $15 \% \mathrm{w} / \mathrm{w}$ of diet) produced a dose-dependent improvement in memory scores of young as well as aged mice. CSL also reversed successfully the memory deficits induced by scopolamine $(0.4 \mathrm{mg} / \mathrm{kg}$, ip) and diazepam (1 $\mathrm{mg} / \mathrm{kg}$, ip). Brain cholinesterase activity and serum total cholesterol levels were considerably reduced by CSL administration in daily diets for 45 days [71-72]. 


\section{Antidepressant effect:}

Diethyl ether extract of seeds of Coriandrum sativum showed more significant antidepressant effect than that of aqueous extract through interaction with adrenergic, dopamine-ergic and GABA-ergic system [73].

\section{Sedative-hypnotic effects:}

The aqueous, hydroalcoholic extracts and essential oil of coriander seeds possessed sedative-hypnotic activity. The aqueous, hydroalcoholic extracts and essential oil of coriander seeds (100, 200, 400 and 600 $\mathrm{mg} / \mathrm{kg}$ ) were intraperitoneally administered to male albino mice, 30 minutes before pentobarbital injection (40 $\mathrm{mg} / \mathrm{kg}$ ). Latency to sleep and sleep duration were recorded. Aqueous extract prolonged pentobarbital-induced sleeping time at 200, 400 and $600 \mathrm{mg} / \mathrm{kg}$. Hydroalcoholic extract at doses of 400 and $600 \mathrm{mg} / \mathrm{kg}$ increased pentobarbital induced sleeping time compared to saline-treated group. The essential oil increased pentobarbitalinduced sleeping time only at $600 \mathrm{mg} / \mathrm{kg}$ [74].

The sleep-prolonging effect of Coriandrum sativum was investigated in mice. The hydroalcoholic extract (HAE) and its three fractions, water (WF), ethyl acetate (EAF) and N-butanol (NBF) were prepared from Coriandrum sativum aerial parts and administrated to mice. The HAE, EAF and NBF significantly prolonged sleep duration. Only the NBF was significantly decreased sleep latency. No decrease in the neuronal surviving was observed either by HAE or by its fractions. The data indicated that Coriandrum sativum exerted sleepprolonging action without major neurotoxic effect [75].

\section{Anticonvulsant effect:}

The effects of hydroalcoholic extract of aerial parts of the plants $(100,500$ and $1000 \mathrm{mg} / \mathrm{kg})$ on brain tissues oxidative damages following seizures induced by pentylenetetrazole (PTZ) was investigated in rats. The extract significantly increased the MCS (latencies to the first minimal clonic seizures) and GTCS (latencies to the first generalized tonic-clonic seizures $) \quad(\mathrm{P}<0.01, \quad \mathrm{P}<0.001)$ following $\mathrm{PTZ}$-induced seizures. The malondialdehyde (MDA) levels in both cortical and hippocampal tissues of PTZ group were significantly higher than those of the control animals $(\mathrm{P}<0.001)$. Pretreatment with the extract prevented elevation of the MDA levels $(\mathrm{P}<0.010-\mathrm{P}<0.001)$. Following $\mathrm{PTZ}$ administration, a significant reduction in total thiol groups was observed in both cortical and hippocampal tissues $(\mathrm{P}<0.050)$. Pre-treatment with the $500 \mathrm{mg} / \mathrm{kg}$ of the extract caused a significant decreased in total thiol concentration in the cortical tissues $(\mathrm{P}<0.010)$. Accordingly, the hydroalcoholic extract of the aerial parts of Coriandrum sativum possessed significant antioxidant and anticonvulsant activities [75].

Intraperitoneal injection of decoction and maceration extracts increased the latency of the convulsions induced by PTZ in albino mice, but failed to produce complete protection against mortality. The anticonvulsant activities of high dose extracts were similar to that of phenobarbital at a dose of $20 \mathrm{mg} / \mathrm{kg}$ in the PTZ test. In the maximal electroshock seizures, the aqueous extracts of seeds (at a dose of $0.5 \mathrm{~g} / \mathrm{kg}$ ) and the ethanolic extract (at doses of 3.5 and $5 \mathrm{~g} / \mathrm{kg}$ ) decreased the duration of tonic seizures by $22.30 \%, 30.43 \%$ and $36.96 \%$, respectively [76-77].

\section{Effect on memory:}

The effects of inhaled coriander volatile oil (1\% and 3\%, daily, for 21days) on spatial memory performance were assessed in an $A \beta(1-42)$ rat model of Alzheimer's disease. The $A \beta(1-42)$-treated rats exhibited the following: decrease of spontaneous alternations percentage within Y-maze task and increase of working memory errors, reference memory errors and time taken to consume all five baits within radial arm maze task. Exposure to coriander volatile oil significantly improved these parameters, suggesting positive effects on spatial memory formation. Assessments of oxidative stress markers in the hippocampal tissue of A $\beta(1-42)$-treated rats showed a significant increase of superoxide dismutase (SOD), lactate dehydrogenase (LDH) and a decrease of glutathione peroxidase (GPX) specific activities along with an elevation of malondialdehyde (MDA) level. Coriander volatile oil significantly decreased SOD and LDH specific activities, increased GPX specific activity and attenuated the increased MDA level. Also, DNA cleavage patterns were absent in the coriander rats, thus suggesting antiapoptotic activity of the volatile oil. Accordingly, the exposure to coriander volatile oil ameliorated $A \beta(1-42)$-induced spatial memory impairment by attenuation of the oxidative stress in the rat hippocampus [78].

The effect of Coriandrum sativum seed extract on learning was studied in second-generation mice. Ethanolic extract $(2 \%)$ of coriander was dissolved in sunflower oil as a vehicle and injected $(100 \mathrm{mg} / \mathrm{kg}$ intraperitoneal $)$ to mother mice during breastfeeding for 25 days at 5-day intervals. After feeding the newborn mice, their learning was evaluated using a step-through passive avoidance task with $0.4 \mathrm{~mA}$ electric shock for 2 or 4 seconds. While coriander extract showed a negative effect in the short term (1 hour) after the training session, it potentiated the mice's learning in later assessments $(24$ hours post-training $[\mathrm{P}=0.022]$ and 1 week post-training $[\mathrm{P}=0.002]$ by a 4-second shock). Low-dose caffeine $(25 \mathrm{mg} / \mathrm{kg}$ ip after training) improved the learning after 1 hour $(\mathrm{P}=0.024)$. No modification in the pain threshold was elicited by electric stimuli both in coriander and control groups [79]. 


\section{Effect on orofacial dyskinesia:}

The effect of ethanolic extract of Coriandrum sativum seeds $(100,200 \mathrm{mg} / \mathrm{kg})$ was studied on tacrine induced orofacial dyskinesia. Tacrine $(2.5 \mathrm{mg} / \mathrm{kg}$, ip) treated animals were observed for vacuous chewing movements (VCM), tongue protrusions (TP) and orofacial bursts $(\mathrm{OB})$ for $1 \mathrm{~h}$ followed by observations for locomotor changes and cognitive dysfunction. Subchronic administration of Coriandrum sativum seed extract (E-CS) $(100,200 \mathrm{mg} / \mathrm{kg}$, po, for 15 days significantly $(\mathrm{P}<0.05)$ decreased the tacrine induced VCM, TP and OB; and also significantly $(\mathrm{P}<0.05)$, increased locomotion and cognition compared to the tacrine treated group. Biochemical analysis revealed that tacrine administration significantly $(\mathrm{P}<0.05)$ decreased the levels of superoxide dismutase (SOD), catalase (CAT), glutathione reductase $(\mathrm{GSH})$ levels and also significantly $(\mathrm{P}<0.05)$ increased lipid peroxidation (LPO) as an index of oxidative stress, whereas subchronic administration of E-CS significantly $(\mathrm{P}<0.05)$ improved the antioxidant enzyme ( $\mathrm{SOD}, \mathrm{CAT}$, and $\mathrm{GSH})$ levels and also significantly $(\mathrm{P}<0.05)$ decreased lipid peroxidation $(\mathrm{LPO})$. The results have demonstrated the protective role of ethanolic extract of Coriandrum sativum against tacrine induced orofacial dyskinesia [80].

\section{Neuroprotective effect}

The neuroprotective effect of Coriandrum sativum was evaluated against ischemic-reperfusion insult in brain. The global cerebral ischemia in albino rats was induced by blocking common carotid arteries for 30 mins followed by 45 mins of reperfusion. At the end of reperfusion period, histological changes, levels of lipid peroxidation, superoxide dismutase, catalase, glutathion, calcium and total protein were measured. Bilateral common carotid artery occlusion produced significant elevation in lipid peroxidation, calcium levels and infarct size, and decrease in endogenous antioxidants such as reduced glutathion, superoxide dismutase and catalase levels. Pretreatment with methanolic extract of leaves of Coriandrum sativum $(200 \mathrm{mg} / \mathrm{kg}$, po) for 15 days increased endogenous enzyme levels of superoxide dismutase, glutathion, catalase and total protein levels, and reduces cerebral infarct size, lipid peroxidation and calcium levels. It also attenuated reactive changes in brain histology like gliosis, lymphocytic infilteration and cellular edema. Accordingly, Coriandrum sativum possessed protective effect in ischemic-reperfusion injury and cerebrovascular insufficiency states [81].

The neuroprotective effect of Coriandrum sativum against glucose/serum deprivation (GSD)-induced cytotoxicity was studied in vitro. The PC12 cells were cultivated for $24 \mathrm{~h}$ in standard media (high-glucose DMEM containing Fetal Bovine Serum) or for $6 \mathrm{~h}$ in GSD condition (glucose-free DMEM, without serum) in the absence or presence of various concentrations $(0.1,0.2,0.4,0.8$ and $1.6 \mathrm{mg} / \mathrm{ml})$ of hydroalcoholic extract (HAE), water fraction (WF), ethyl acetate fraction (EAF) or N-butanol fraction (NBF) of Coriandrum sativum. At the end of the treatments, the cell viability was determined using MTT assay. With the exception of $1.6 \mathrm{mg} / \mathrm{ml} \mathrm{of}$ EAF or NBF which decreased cell survival, the HAE and its fractions exhibited no cytotoxicity under standard condition. Exposure of the cells to GSD condition showed 52\% decrease in the viability. Accordingly, the HAE, EAF and NBF not only failed to increase cell viability but also increased the toxicity. On the other hand, WF at $0.4,0.8$ and $1.6 \mathrm{mg} / \mathrm{ml}$ significantly attenuated the GSD-induced decrease in cell survival. The study revealed that Coriandrum sativum bearing water-soluble compound(s) could induce neuroprotective activity, while, some constituents from this plant may serve as cytotoxic agents under stressful conditions like hypoglycemia [82].

\section{Antibacterial, antifungal, anthelmintic and insecticidal effects:}

The antibacterial effect of aqueous and ethanolic extracts of different coriander parts was studied against nine different pathogenic bacteria isolated from urine, blood, stool and cerebraspinal fluid of different patients (Burkhella capacia, Escherichia coli, Enterobacter cloacae, Gamella morbillorum, $\alpha$-Haemolytic streptococci, Klebsiella pneumonia, Proteus mirabilis, Streptococcus pneumonia, and Salmonella typhi). Cold aqueous extract of coriander seeds had inhibitory effect against some tested bacteria. On the other hand, ethanolic extracts of seeds, leaves and stems showed wide range of antibacterial activity and the highest values for inhibition zone was recorded against Klebsiella pneumoniae and Proteus mirabilis [83].

Essential oils from commercial samples of coriander were assayed for their antibacterial and antifungal activities. Twenty-five genera of bacteria and one fungal species (Aspergillus niger) were used as test organisms. The essential oils showed a high degree of inhibition against all the tested microorganisms [84].

The antimicrobial activity of ethanol, methanol, acetone, chloroform, hexane and petroleum ether extracts of Coriandrum sativum was investigated against infectious pathogenic bacteria such as E. coli, Pseudomonas aeruginosa, Staphylococcus aureus and Klebsiella Pneumonia; and many fungi including Aspergillus niger, Candida albicans, Candida kefyr and Candida tropicalis using agar well diffusion method. The methanol extract of Coriandrum sativum showed more antibacterial activity against Staphylococcus aureus (zone of diameter $12.17 \pm 0.29 \mathrm{~mm})$ and Klebsiella pneumonia zone $(12.17 \pm 0.15 \mathrm{~mm})$, while, it showed more antifungal activity against Candida albicans (zone of diameter $14.20 \pm 0.20 \mathrm{~mm}$ ) and Aspergillus niger $(10.10 \pm 0.10 \mathrm{~mm})$. It appeared that methanol extract showed a varying degree of antibacterial and antifungal effects more than ethanol, acetone, chloroform, hexane and petroleum ether extracts [85]. 
The antibacterial potential of the leaf essential oil, petroleum ether, chloroform, ethyl acetate and methanol extracts of the leaves of Coriandrum sativum were studied against human pathogenic bacteria (Bacillus cereus, Enterobacter faecalis, Salmonella paratyphi, Staphylococcus aureus, Escherichia coli, Proteus vulgaris, Klebsiella pneumoniae, Pseudomonas aeruginosa and Serratia marcescens) by agar well diffusion method. Leaf essential oil as well as leaf ethyl acetate, chloroform and methanol extracts of Coriandrum sativum exhibited pronounced activity against Gram-positive and Gram-negative bacteria and their activity was quite comparable with the standard antibiotics such as tobramycin, gentamicin sulphate, ofloxacin and ciprofloxacin screened under similar conditions [86].

The antibacterial effect of Coriandrum sativum essential oil against Gram-positive and Gram-negative bacteria was evaluated using classical microbiological techniques concomitantly with the use of flow cytometry for the evaluation of cellular physiology. The results showed that coriander oil has an effective antimicrobial activity against all tested bacteria. Propidium iodide incorporation and concomitant loss of all other cellular functions such as efflux activity, respiratory activity and membrane potential seem to suggest that the primary mechanism of action of coriander oil was membrane damage, resulted in cell death [87].

Aliphatic (2E)-alkenals and alkanals isolated from the fresh leaves of the Coriandrum sativum were found to possess bactericidal activity against Salmonella choleraesuis ssp. choleraesuis ATCC 35640. (2E)-Dodecenal (C12) was the most effective against this food-borne bacterium with the minimum bactericidal concentration (MBC) of $6.25 \mathrm{microg} / \mathrm{ml}$ (34 microM), followed by (2E)-undecenal (C11) with an MBC of $12.5 \mathrm{microg} / \mathrm{ml}(74$ microM). The time-kill curve study showed that these alpha, beta-unsaturated aldehydes were bactericidal against $S$. choleraesuis at any growth stage and that their bactericidal action came in part from the ability to act as nonionic surfactants [88-89].

Twelve essential oils were tested in vitro for antimicrobial activities against several strains of Campylobacter jejuni, a pathogen causing food-borne diseases worldwide. Coriander oil exhibited the strong antimicrobial activity against all tested strains. In evaluating the antimicrobial potency of coriander oil against $C$. jejuni on beef and chicken meat at 4 degrees $\mathrm{C}$ and 32 degrees $\mathrm{C}$, it reduced the bacterial cell load in a dosedependent manner. The type of meat and temperature did not influence the antimicrobial activity of the oil [90]. Antimicrobial effect of essential oils from the seeds of Coriandrum sativum was studied against gram-positive bacteria, gram-negative bacteria and Saccharomyces cerevisiae. Essential oil appeared effective against Listeria monocytogenes [91].

The antibacterial potential of two commercial essential oils (EOs) from Coriandrum sativum was studied against vaginal clinical strains of bacteria and yeast. Antimicrobial activities were determined using macro-diffusion (disc, well) and micro-dilution method against twelve clinical strains of bacteria: Escherichia coli, Proteus mirabilis, S. aureus and Enterococcus sp., S. aureus ATCC 25923, ATCC 6538 and Escherichia coli 25922 and two clinical Candida albicans ATTC 10231 strains. An antimicrobial effect of EOs was strain specific. Bactericidal activity was higher for coriander EO (MICs $0.4-45.4 \mu \mathrm{l} / \mathrm{ml}$ ) against almost all tested bacteria, except multiple resistant strains of Eneterococcus sp. and Proteus sp. It showed low fungicidal activity [92].

Antimicrobial activities of essential oils were evaluated against Staphylococcus aureus, Escherichia coli, Pseudomonas aeruginosa and Candida albicans by microdilution method. The essential oils of Coriandrum sativum fruits obtained by hydrodistillation (HD EO) showed greater activity against Staphylococcus aureus and Candida albicans than that obtained by microwave-assisted hydrodistillation (MAHD EO). Moreover, their activities against $E$. coli and $P$. aeruginosa were the same with minimum inhibitory concentration, MIC 0.781 and $6.25 \mu \mathrm{l} / \mathrm{ml}$, for HD EO and MAHD EO respectively [56].

The antibacterial activity of essential coriander oil (ECO) on bacteria with dermatological relevance and skin tolerance of antimicrobial effective ECO concentrations were investigated. Essential coriander oil showed good antibacterial activity towards the majority of the bacterial strains tested, including Streptococcus pyogenes (Lancefield group A) and methicillin resistant Staphylococcus aureus (MRSA), with mean minimal inhibitory concentrations of $0.04 \% \mathrm{v} / \mathrm{v}$ and $0.25 \% \mathrm{v} / \mathrm{v}$, respectively. The skin tolerance of a cream and a lotion containing $0.5 \%$ and $1.0 \%$ ECO was assessed in 40 healthy volunteers using the occlusive patch test. No skin irritation could be observed by sensitive photometric assessment in any of the volunteers. The authors suggested that, because of its activity against Streptococcus pyogenes, Staphylococcus aureus and MRSA, with excellent skin tolerance, ECO might be useful as an antiseptic for the prevention and treatment of skin infections with Gram-positive bacteria [93].

A series of experiments were conducted to evaluate the ability of cilantro oil (the essential oil of Coriandrum sativium) to control the growth of Listeria monocytogenes on vacuum-packed ham. The in vitro minimal inhibitory concentration for five strains of L. monocytogenes was found to vary from $0.074 \%$ to $0.018 \%$ depending on strain. Cilantro oil treatments were then tested on ham disks inoculated with a cocktail of the five L. monocytogenes strains. The concentrations studied were $0.1 \%, 0.5 \%$, and $6 \%$ cilantro oil diluted in sterile canola oil or incorporated into a gelatin gel in which lecithin was used to enhance incorporation of the 
cilantro oil. Gelatin gel treatments were also conducted with $1.4 \%$ monolaurin with or without $6 \%$ cilantro oil to determine if an interaction between the antimicrobials could increase inhibition of L. monocytogenes. Treated ham was then vacuum-packed and stored at 10 degrees $\mathrm{C}$ for up to 4 weeks. The only cilantro oil treatment which inhibited growth of L. monocytogenes on the ham samples was $6 \%$ cilantro oil gel. Samples receiving this treatment had populations of L. monocytogenes $1.3 \mathrm{log} \mathrm{CFU} / \mathrm{ml}$ lower than controls at week 1 of storage, there was no difference between treatments from week 2 onward. It appears that immobilization of the antimicrobial in a gel enhanced the effect of treatments [94].

The hydroalcoholic extract of the crude Coriandrum sativum was screened for antibacterial activity against various bacterial species by disk diffusion method. Assay was performed using clinical isolates of $B$. cereus, S. aureus, $P$. aeruginosa and E. coli. Crude extract of Coriandrum sativum was effective only against Bacillus cereus [95].

The synergistic antibacterial effect between Coriandrum sativum essential oil and six different antibacterial drugs (cefoperazone, chloramphenicol, ciprofloxacin, gentamicin, tetracycline and piperacillin) was investigated. The antibacterial activity of coriander oil was assessed using microdilution susceptibility testing and synergistic interaction by checkerboard assays. The association of coriander essential oil with chloramphenicol, ciprofloxacin, gentamicin and tetracycline against Acinetobacter baumannii showed in vitro effectiveness, which was an indicator of a possible synergistic interaction against two reference strains of $A$. baumannii (LMG 1025 and LMG 1041, FIC index from 0.047 to 0.375). However, when tested the involvement between coriander essential oil and piperacillin or cefoperazone, the isobolograms and FIC index showed an additive interaction. The in vitro interaction could improve the antimicrobial effectiveness of ciprofloxacin, gentamicin and tetracycline and may contribute to resensitize A. baumannii to the action of chloramphenicol [96].

$\mathrm{T}$ he antifungal activity of essential oil from Coriandrum sativum fruits was evaluated against Microsporum canis and Candida spp. by the agar-well diffusion method and the minimum inhibitory concentration (MIC) and the minimum fungicidal concentration (MFC) were established by the broth microdilution method. The essential oil induced growth inhibition zones of $28 \pm 5.42$ and $9.25 \pm 0.5 \mathrm{~mm}$ for $M$. canis and Candida spp. respectively. The MICs and MFCs for M. canis strains ranged from 78 to 620 and 150 to $1.250 \mu \mathrm{g} / \mathrm{ml}$, and the MICs and MFCs for Candida spp strains ranged from 310 to 620 and 620 to $1.250 \mu \mathrm{g} / \mathrm{ml}$, respectively [97].

The antifungal activity of coriander essential oil was studied on germ tube formation, and the potential synergism with amphotericin B were also studied. Coriander essential oil has a fungicidal activity against the Candida strains tested, with MLC values equal to the MIC value and ranging from 0.05 to $0.4 \%$ (v/v). Flow cytometric evaluation of BOX, PI and DRAQ5 staining indicated that the fungicidal effect was a result of cytoplasmic membrane damage and subsequent leakage of intracellular components such as DNA. Also, concentrations bellow the MIC value caused a marked reduction in the percentage of germ tube formation for C. albicans strains. A synergetic effect between coriander oil and amphotericin B was also recorded against $C$. albicans strains, while for $C$. tropicalis strain only an additive effect was observed [98].

The antifungal activity and mode of action of the essential oils (EO) from Coriandrum sativum leaves were evaluated against Candida spp. In addition, the molecular targets affected in whole-genome expression in human cells was also studied. The EO showed anticandidal effects. Coriandrum sativum EO may bind to membrane ergosterol, increasing ionic permeability and causing membrane damage leading to cell death, but it did not act on cell wall biosynthesis-related pathways. The EO also inhibited Candida biofilm adherence to a polystyrene substrate at low concentrations, and decreased the proteolytic activity of Candida albicans at the minimum inhibitory concentration. In addition, the EO and its selected active fraction had low cytotoxicity on human cells [99]. Coriandrum sativum essential oil possessed antifungal activity against Candida species isolates from the oral cavity of patients with periodontal disease. 2-hexen-1-ol, 3-hexen-1-ol and cyclodecane were determined as the active constituents in the oil [100].

The efficacy and tolerability of $6 \%$ coriander oil was tested in unguentum leniens in the treatment of interdigital tinea pedis. The study was performed on 40 participants. $6 \%$ coriander oil showed highly significant improvement of the clinical signs in unguentum leniens $(p<0.0001)$ during the entire observation period. The number of positive fungal cultures also decreased $(\mathrm{p}=0.0654)$. The tolerability of the tested substances was good [101].Commercial essential oils from 28 plant species were tested for their nematicidal activities against the pine wood nematode, Bursaphelenchus xylophilus. The best nematicidal activity against B. xylophilus was achieved with essential oils of coriander (Coriandrum sativum) [102].In vitro anthelmintic activities of crude aqueous and hydro-alcoholic extracts of the seeds of Coriandrum sativum were investigated on the egg and adult nematode parasite Haemonchus contortus. The aqueous extract of Coriandrum sativum was also investigated for in vivo anthelmintic activity in sheep infected with Haemonchus contortus. Both extracts of Coriandrum sativum inhibited hatching of eggs completely at a concentration less than $0.5 \mathrm{mg} / \mathrm{ml}$. $\mathrm{ED}_{50}$ of aqueous extract of Coriandrum sativum was $0.12 \mathrm{mg} / \mathrm{ml}$ while that of hydroalcoholic extract was $0.18 \mathrm{mg} / \mathrm{ml}$. There was no 
statistically significant difference between aqueous and hydroalcoholic extracts ( $>0.05)$. The hydroalcoholic extract showed better in vitro activity against adult parasites than the aqueous one. For the in vivo study, sheep were artificially infected with Haemonchus contortus, crude aqueous extract of Coriandrum sativum was given at 0.45 and $0.9 \mathrm{~g} / \mathrm{kg}$ dose levels. Efficacy was tested by faecal egg count reduction (FECR) and total worm count reduction (TWCR). On day 2 post treatment, significant FECR was detected in groups treated with higher dose of Coriandrum sativum $(\mathrm{p}<0.05)$ and albendazole $(\mathrm{p}<0.001)$. Significant $(\mathrm{p}<0.05)$ TWCR was detected only for higher dose of Coriandrum sativum compared to the untreated group. Reduction in male worms was higher than female worms. Treatment with both doses of Coriandrum sativum did not help the animals to improve or maintain their PCV, while those treated with albendazole showed significant increase in PCV $(p<0.05)$ [103].

The antiparastic efficacy of Coriandrum sativum essential oils was studied by two in vitro assays on Haemonchus contortus using egg hatch test (EHT) and larval development test (LDT). Coriandrum sativum essential oils exhibited a dose-dependent effect in the EHT, inhibiting $81.2 \%$ of $H$. contortus larvae hatching, at a concentration of $2.5 \mathrm{mg} / \mathrm{ml}$. The effective concentration to inhibit $50 \%\left(\mathrm{EC}_{50}\right)$ of egg hatching was $0.63 \mathrm{mg} / \mathrm{ml}$. In LDT, Coriandrum sativum at concentration of $10 \mathrm{mg} / \mathrm{ml}$ inhibited $97.8 \%$ of $H$. contortus larval development [104].

The in vitro effect of fractions from Coriandrum sativum (coriander) on promastigotes and amastigotes of $L$. infantum was studied in addition to its toxicity against the murine monocytic cells RAW 264.7. All fractions were effective against $L$. infantum promastigotes and did not differ from the positive control pentamidine ( $\mathrm{p}>0.05)$. However, the Coriandrum sativum methanol fraction, was the most effective against amastigotes and did not differ from the positive control amphotericin B ( $p>0.05)$ [105].

The biological activity of essential oil of Coriandrum sativum seeds was tested against adult Tribolium confusum Duval (Coleoptera: Tenebrionidae) and Callosobruchus maculatus F. (Coleoptera: Bruchidae) in a series of laboratory experiments. The mortality of 1-7 day old adults of the insect pests increased with concentration from 43 to $357 \mu \mathrm{l} / 1$ air and with exposure time from 3 to $24 \mathrm{~h}$. In the probit analysis, $\mathrm{LC}_{50}$ values showed that $C$. maculatus $\left(\mathrm{LC}_{50}=1.34 \mu \mathrm{l} / 1\right.$ air $)$ was more susceptible than $T$. confusum $\left(\mathrm{LC}_{50}=318.02 \mu \mathrm{l} / 1\right.$ air $)$ to seed essential oil of Coriandrum sativum [106].

The essential oil (EO) of the fruits of Coriandrum sativum was evaluated for its larvicidal and repellent activities against Aedes albopictus Skuse (Diptera: Culicidae). Coriandrum sativum EO exerted toxic activity against $A$. albopictus larvae: $\mathrm{LC}_{50}$ was $421 \mathrm{ppm}$, while $\mathrm{LC}_{90}$ was $531.7 \mathrm{ppm}$. Repellence trials highlighted that Coriandrum sativum $\mathrm{EO}$ was a good repellent against A. albopictus, $\mathrm{RD}_{50}$ was $0.0001565 \mu \mathrm{l} / \mathrm{cm}^{2}$ of skin, while $\mathrm{RD}_{90}$ was $0.002004 \mu \mathrm{l} / \mathrm{cm}^{2}$. At the highest dosage $\left(0.2 \mu \mathrm{l} / \mathrm{cm}^{2}\right.$ of skin), the protection time achieved with Coriandrum sativum essential oil was higher than 60 min [107].

The leaf oil had significant toxic effects against the larvae of Aedes aegypti with an $\mathrm{LC}_{50}$ value of $26.93 \mathrm{ppm}$ and an $\mathrm{LC}_{90}$ value of $37.69 \mathrm{ppm}$, and the stem oil has toxic effects against the larvae of $A$. aegypti with an $\mathrm{LC}_{50}$ value of $29.39 \mathrm{ppm}$ and an $\mathrm{LC}_{90}$ value of $39.95 \mathrm{ppm}$ [58].

The seed oil had significant toxic effects against the larvae of Aedes aegypti with an $\mathrm{LC}_{50}$ value of $21.55 \mathrm{ppm}$ and $\mathrm{LC}_{90}$ value of $38.79 \mathrm{ppm}$. The major components in the essential oil of coriander play an important role as immunotoxicity on the $A$. aegypti [53].

\section{Antioxidant effect:}

Coriandrum sativum has a very effective antioxidant profile showing 2,2-diphenyl-1-picrylhydrazyl (DPPH) radical scavenging activity, lipoxygenase inhibition, phospholipid peroxidation inhibition, iron chelating activity, hydroxyl radical scavenging activity, superoxide dismutation, glutathione reduction and antilipid peroxidation due to its high total phenolic content $[61,108-110]$.

The fresh juice exhibited high antioxidant activities, evidenced by its ability to scavenge hydroxyl- and superoxide-radicals, high reducing power, and protection against biological macromolecular oxidative damage and by increasing the level of glutathione [111].

Among the leaf essential oil and leaf petroleum ether, chloroform, ethyl acetate and methanol extracts of Coriandrum sativum studied, methanol extract and leaf essential oil showed potent scavenging activity on 1, 1diphenyl-2-picrylhydrazyl (DPPH) radical [86].

The in vitro antioxidant potential of aqueous leaf extracts of Coriandrum sativum leaves was determined qualitatively. Enzymatic antioxidant analysis in the extract of Coriandrum sativum: Catalase $\left(\mu /\right.$ moles of $\mathrm{H}_{2} \mathrm{O}_{2}$ decomposed $/ \mathrm{min} / \mathrm{g}$ protein, 1 unit $=\mu / \mathrm{moles}$ of $\mathrm{H}_{2} \mathrm{O}_{2}$ decomposed $/ \mathrm{min} / \mathrm{g}$ protein $)=3.135$; peroxidase $(\mathrm{Unit} / \mathrm{mg}$ protein, 1 unit $=\mathrm{mg}$ of GSH utilized $/ \mathrm{min})=2.508 \times 10^{3}$; ascorbate oxidase $(\mu \mathrm{mole} / \mathrm{ml}, 1$ unit $=0.01 \mathrm{O} . \mathrm{D}$ change/min) $=100.262[48]$.

The amount of the total phenolic contents (TPC) in the aqueous extract of Sudanese Coriandrum sativum was $1654 \pm 3.4 \mathrm{mg} \mathrm{GAE} / \mathrm{L}$. The results of the in vitro antioxidant activity by $\beta$-carotene/linoleic acid assay, showed that Coriandrum sativum aqueous extract had strong antioxidant activity $(84.6 \%$ at $400 \mathrm{ug} / \mathrm{ml})$, when compared with the standard reference Tert-butyl hydroquinone (TBHQ) $(99.5 \%$ at the same 
concentrations). The aqueous extract showed strong DPPH free-radical scavenging activity $(88.5 \%$ at $400 \mathrm{ug} / \mathrm{ml})$, compared with the standard reference (TBHQ) $(99.73 \%$ at the same concentration) [55].

The pre-feeding of rats with coriander seed powder (CSP) at $10 \%$ level was found to reduce the experimentallyinduced (HCH-induced) rise in conjugated dienes, hydroperoxide and malondialdehyde (MDA) contents in the liver [112].

The antiperoxidative effect of coriander seeds (Coriandrum sativum) was studied in rats administered high fat diet. Significant decrease in the levels of lipid peroxides, free fatty acids and glutathione were observed when compared to control group whereas the activity of antioxidant enzymes was increase [113].

Phenolic content and antioxidant activity were evaluated in the coriander leaves and seeds. The results revealed that serum alanine aminotransferase (ALT), aspartate aminotransferase (AST) and alkaline phosphatase (ALP) activities were significantly increased in thioacetamide (TAA)-induced hepatotoxicity groups compared to the normal control. Oxidative stress was manifested by a significant rise in nitric oxide (NO), thiobarbituric acid reactive substance (TBARS) levels and myloperoxidase (MPO) activities in the liver tissues, in induction group compared with the control. Rats fed with coriander leaves and seeds showed a decrease in the serum ALT, AST and ALP activities and in the liver NO and TBARS levels as compared to the induction group. Histopathological study revealed that coriander feeding attenuated TAA-induced hepatotoxicity in rats [114].

The production of antioxidants in vegetative parts (leaves and stems) of in vivo and in vitro grown coriander samples was studied and compared. The antioxidant activity was evaluated by radical scavenging activity, reducing power and lipid peroxidation inhibition. The in vivo sample showed the highest antioxidant activity, which appeared proportional to levels of hydrophilic compounds. Otherwise, in vitro samples, gave the highest concentration of lipophilic compounds but a different profile when compared to the in vivo sample [115]. The antioxidant and free radical scavenging property of seeds were evaluated in addition to investigation whether the administration of seeds affected the oxidative stress in the kidney of streptozotocin-induced diabetic rats. Incorporation of seed powder in the diet led to marked lowering of blood glucose and a rise in the levels of insulin in diabetic rats. A parallel beneficial effect was observed on oxidant -antioxidant balance in the kidney. Addition of coriander seed powder not only inhibited the process of peroxidative damage but also significantly reactivated the antioxidant enzymes and antioxidant levels in diabetic rats. The seeds also showed scavenging activity against superoxides and hydroxyl radicals in a concentration-dependent manner. Maximum free radicalscavenging action and free radical reducing power of coriander seed was observed at a concentration of 50 microg GAE. Islet histology structures showed degeneration of pancreatic islets in diabetic rats which was also reduced in diabetic rats treated with seed powder [63].

The hydroalcohol extract of Coriandrum sativum leaves at the dose of $1 \mathrm{mg} / \mathrm{ml}$ was subjected to a series of in vitro assays (2, 2'- diphenyl-1-picrylhydrazyl, lipid peroxidation by thiobarbituric acid, reducing power and nitric oxide (NO) radical scavenging) in order to study its antioxidant efficacy. The amount of flavonoids in $70 \%$ ethanol extract was found to be $44.5 \mu \mathrm{g}$ and that of the total phenols was $133.74 \mu \mathrm{g}$ gallic acid equivalents per $\mathrm{mg}$ extract. The extracts of the leaves showed metal chelating power, with $\mathrm{IC}_{50}$ value of $368.12 \mu \mathrm{g} / \mathrm{ml}$, whereas that of standard EDTA was $26.7 \mu \mathrm{g} / \mathrm{ml}$. The $\mathrm{IC}_{50}$ values for 2, 2'-azino-bis (3ethylbenzothiazoline-6-sulphonic acid radical scavenging was $222 \mu \mathrm{g} / \mathrm{ml}$, whereas that of standard ascorbic acid was $22.6 \mu \mathrm{g} / \mathrm{ml}$. The NO scavenging activity of the extract of the leaves showed $\mathrm{IC}_{50}$ value of $815.6 \mu \mathrm{g} / \mathrm{ml}$; at the same time the standard BHA had $49.1 \mu \mathrm{g} / \mathrm{ml}$. All the plant extracts provided DNA damage protection; however, the protection provided at the dose of $8 \mu \mathrm{g} / \mathrm{ml}$ was comparable to that of standard gallic acid. The Coriandrum sativum leaf extract was able to prevent in vitro lipid peroxidation with $\mathrm{IC}_{50}$ value of $589.6 \mu \mathrm{g} / \mathrm{ml}$, whereas that of standard BHA was $16.3 \mu \mathrm{g} / \mathrm{ml}$. The results also showed significant ferric reducing power indicating the hydrogen donating ability of the extract [64].

\section{Hypolipidemic effect:}

The antilipidemic activity of fresh leaves of Coriandrum sativum was studied against salbutamol induced cardiac injury in rabbits. Salbutamol administered rabbits $(50 \mathrm{mg} / \mathrm{kg}$ ) showed elevated level of serum lipids (LDL-cholesterol, triglyceride) and decreased level of HDL-cholesterol and antioxidant enzymes (SOD, CAT). Both the pre- and post treatment of plant extract $(100 \mathrm{mg} / \mathrm{kg})$ for three weeks exerted significant antilipidemic effect against salbutamol-induced myocardial infarction by lowering the level of serum LDLcholesterol, triglycerides and peroxidase and increasing the level of HDL-cholesterol and antioxidant enzymes [116].

The hypolipidemic and antioxidant action of Coriandrum sativum were investigated in cholesterol-fed rabbits. Cholesterol feeding $(500 \mathrm{mg} / \mathrm{kg}$ bw/day) for 120 days caused a significant increase in serum total cholesterol, phospholipid, triglyceride, LDL-cholesterol and VLDL-cholesterol levels, whereas HDL ratio was decreased significantly when compared with control group. The changes in the antioxidant parameters were accompanied by an increase in hepatic lipid peroxidation and reduction in glutathione (GSH) and catalase activity. The level of lipid peroxidation was reduced whereas GSH content and catalase activity were elevated 
after the treatment with $70 \%$ methanolic extract of Coriandrum sativum at a dose of $500 \mathrm{mg} / \mathrm{kg}$ bw/day. Reduced serum lipid profile and elevated HDL ratio was observed after administration of Coriandrum sativum. Coriandrum sativum extract feeding increased the faecal excretion of cholesterol and phospholipids. Histological studies showed less cholesterol deposits in the aorta of high cholesterol diet animals given Coriandrum sativum compared to the high cholesterol diet untreated animals [117].

In the biphasic model of triton-induced hyperlipidemia, Coriandrum sativum at a dose of $1 \mathrm{~g} / \mathrm{kg}$ body weight reduced cholesterol and triglycerides levels in both synthesis and excretory phases in rats. The results revealed that coriander decreases the uptake and enhances the breakdown of lipids [118].

The antiperoxidative effect of coriander seeds was studied in rats administered high fat diet. Significant decrease in the levels of lipid peroxides, free fatty acids and glutathione was observed when compared to control group whereas the activity of antioxidant enzymes were increased [119].

Coriandrum sativum seeds were incorporated into diet, and the effect of the of coriander seeds on the metabolism of lipids was studied in rats fed with high fat diet and added cholesterol. The seeds had a significant hypolipidemic action. In the experimental group of rats (tissue) the level of total cholesterol and triglycerides increased significantly. There was significant increase in beta-hydroxy, beta-methyl glutaryl CoA reductase and plasma lecithin cholesterol acyl transferase activity were noted in the experimental group. The level of low density lipoprotein (LDL) and very low density lipoprotein (VLDL) cholesterol were decreased, while that of high density lipoprotein (HDL) cholesterol was increased compared to the control group [120-121].

The potential effects of dietary supplementation of coriander seed (as a lipolytic and antioxidant) was investigated on carcass lipid composition of quails. Dietary supplementation of coriander seed affected the lipid composition of carcass greatly by decreasing saturated fatty acid (SFA) contents (palmitic and stearic acids) and by increasing monounsaturated and polyunsaturated fatty acid (MUFA and PUFA) in comparison with the control group ( $\mathrm{p}<0.01)$. The highest dosage of coriander seed ( $4 \%$ added to the ration) systematically induced the greatest effects on fatty acid composition. Some of the acids present in coriander viz. linoleic acid, oleic acid, palmitic acid, stearic acid and ascorbic acid were very effective in reducing the cholesterol level in the blood. They also reduced the cholesterol deposition in the inner walls of the arteries and veins [122].

The efficacy of Coriandrum sativum (CS) in preventing in vitro low density lipoprotein (LDL) oxidation mediated macrophage modification was studied in rats. The efficacy of CS seed extract in alleviating pathophysiological alterations of high cholesterol diet induced atherosclerosis was also investigated in rats. High cholesterol fed atherogenic rats showed elevated lipid indices, evidences of LDL oxidation, plaque formation in thoracic aorta. The same was further validated with immune-staining of cell adhesion molecules and hematoxylin and eosin (HXE) staining. However, co-supplementation of CS to atherogenic rats recorded significant lowering these parameters, CS extract was also prevented onset and progression of atherosclerosis [123].

\section{Anti-inflammatory and analgesic effects:}

The anti-inflammatory and anti-granuloma activities of Coriandrum sativum hydroalcoholic extract (CSHE) was studied in experimental models. The anti-inflammatory activity of CSHE was evaluated using carrageenan-induced paw edema model and the anti-granuloma activity of CSHE was evaluated using the subcutaneous cotton pellet implantation-induced granuloma formation and stimulation of peritoneal macrophages with complete Freund's adjuvant. Serum tumor necrosis factor- $\alpha$ (TNF- $\alpha$ ), IL-6, IL-1 $\beta$ levels, and peritoneal macrophage expression of TNF-R1 were evaluated as markers of global inflammation. CSHE at the highest dose $(32 \mathrm{mg} / \mathrm{kg})$ produced a significant reduction $(\mathrm{p}<0.05)$ in paw edema after carrageenan administration. CSHE treatment also reduced dry granuloma weight in all treated animals. Serum IL-6 and IL-1 $\beta$ levels were significantly $(\mathrm{p}<0.05)$ lower in the CSHE $(32 \mathrm{mg} / \mathrm{kg})$-treated group as compared to control. Although there was an increase in serum TNF- $\alpha$ level in the CSHE-treated group as compared to control, but TNF-R1 expression on peritoneal macrophages was reduced [124].

The anti-inflammatory and analgesic effects of Coriandrum sativum seeds were evaluatedin animal model. Carrageenan test was used for evaluation of anti-inflammatory effect, while, writhing and formalin tests were used for evaluation of analgesic effects. The results showed that coriander had no anti-inflammatory effect in carrageenan test. In writhing test, only the essential oil $(4 \mathrm{ml} / 100 \mathrm{~g}$, po $)$ had a significant effect $(\mathrm{p}<0.01)$. Total extract, polyphenolic extract and essential oil of coriander, had significant effect in both phases of formalin test [125].

The role of opiate system in the antinociceptive effects of Coriandrum sativum (CS) was studied in acute and chronic pain in mice using hot plate (HP), tail flick (TF) and formalin (FT) tests, and its effects were compared with dexamethasone (DEX) and stress (ST). CS (125 250, 500 and $1000 \mathrm{mg} / \mathrm{Kg}$ IP), DEX (0.5, 1 and $2 \mathrm{mg} / \mathrm{Kg}$ IP), vehicle (VEH) or swim stress were used 30 min before the pain evaluation tests. Acute and chronic pain was assessed by HP, TF and FT models. In addition, Naloxone (NAL, $2 \mathrm{mg} / \mathrm{Kg}$, IP) was injected $15 \mathrm{~min}$ before the CS extract administration in order to assess the role of opiate system in the antinociception of CS. Results indicated that CS, DEX and ST have analgesic effects $(\mathrm{p}<0.01)$ in comparison with the control group and higher 
dose of CS was more effective ( $\mathrm{p}<0.001)$. Pretreatment with NAL modulated the antinociceptive effects of CS in all models $(\mathrm{p}<0.001)$. The findings showed an interaction between antinociceptive effects of CS and opiate system [126].The analgesic effects of the extract were assessed using hot plate method. Aqueous extract at 50, 100 and $200 \mathrm{mg} / \mathrm{kg}$ significantly produce analgesic activity compared to control group [65].

The anti-inflammatory activity of ethanolic extract of Coriandrum sativum was studied using carrageenan induced paw edema in albino rats. Ethanolic leaf extract of Coriandrum sativum was used as $200 \mathrm{and} 400 \mathrm{mg} / \mathrm{kg}$. Oral administration of Coriandrum sativum ethanolic leaf extract of $400 \mathrm{mg} / \mathrm{kg} / \mathrm{ip}$ was more effective antiinflammatory than $200 \mathrm{mg} / \mathrm{kg} / \mathrm{ip}$ [127].The antiarthritic activity of Coriandrum sativum seed hydroalcoholic extract (CSHE) was evaluated in adult rats by using two experimental models (formaldehyde and complete Freund's adjuvant (CFA) induced arthritis). The expression of pro-inflammatory cytokines (predominantly contributed by macrophages) was also evaluated. TNF- $\alpha$ level was estimated in serum. TNF-R1, IL-1 $\beta$ and IL-6 expression were also analysed in the synovium. CSHE produced a dose dependent inhibition of joint swelling as compared to control animals in both formaldehyde and CFA induced arthritis. Although there was a dose dependent increase in serum TNF- $\alpha$ levels in the CSHE treated groups as compared to control, the synovial expression of macrophage derived pro-inflammatory cytokines/cytokine receptor was found to be lower in the CSHE treated groups as compared to control [128]. The protective effects of Coriandrum sativum on acetic acid-induced colitis was investigated in rats. Treatment was carried out using three increasing doses of extract $(250,500,1000 \mathrm{mg} / \mathrm{kg})$ and essential oil $(0.25,0.5,1 \mathrm{ml} / \mathrm{kg})$ of coriander started $2 \mathrm{~h}$ before colitis induction and continued for a five-day period. Colon biopsies were taken for weighting, macroscopic scoring of injured tissue, histopathological examination and measuring myeloperoxidase (MPO) activity. Colon weight was decreased in the groups treated with extract (500 and $1000 \mathrm{mg} / \mathrm{kg}$ ) and essential oil $(0.5 \mathrm{ml} / \mathrm{kg})$ compared to the control group. Regarding MPO levels, ulcer severity and area as well as the total colitis index, the results indicated that the treatment with extract and essential oil induced meaningful alleviation of colitis [129].

A polyherbal ayurvedic formulation from an ancient authentic classical text of ayurveda was evaluated for its activity against inflammatory bowel disease (IBD). The polyherbal formulation contained four different drugs viz., Bilwa (Aegle marmeloes), Dhanyak (Coriandrum sativum), Musta (Cyperus rotundus) and Vala (Vetiveria zinzanioids). The formulation has been tried in clinical practice and was found to be useful in certain number of cases of IBD. Accordingly, the same form, decoction (aqueous extract) was evaluated in experimental animals. The formulation was tried on two different experimental animal models of inflammatory bowel disease (acetic acid-induced colitis in mice and indomethacin-induced enterocolitis in rats). Prednisolone was used as the standard drug for comparison. The formulation showed significant inhibitory activity against inflammatory bowel disease induced in these experimental animal models. The activity was comparable with the standard drug prednisolone. The results obtained established the efficacy of this polyherbal formulation against inflammatory bowel diseases [130].

The anti-inflammatory ability of the aerial parts (stem and leaf) of Coriandrum sativum was investigated on lipopolysaccharide (LPS)-stimulated RAW 264.7 macrophages. The molecular mechanism underlying the pharmacological properties of Coriandrum sativum was also investigated. Ethanolic extracts from both stem and leaf of Coriandrum sativum (CSEE) significantly decreased LPS-induced nitric oxide and prostaglandin $\mathrm{E}_{2}$ production as well as inducible nitric oxide synthase, cyclooxygenase-2, and pro-interleukin1 beta expression. Moreover, LPS-induced IkappaB-alpha phosphorylation and nuclear p65 protein expression as well as nuclear factor-kappaB (NF-kappaB) nuclear protein-DNA binding affinity and reporter gene activity were dramatically inhibited by aerial parts of CSEE. Exogenous addition of CSEE stem and leaf significantly reduced LPS-induced expression of phosphorylated mitogen-activated protein kinases (MAPKs). The authors concluded that CSEE had a strong anti-inflammatory property which inhibited pro-inflammatory mediator expression by suppressing NF-kappaB activation and MAPK signal transduction pathway in LPS-induced macrophages [131].

The anti-inflammatory potency of coriander oil was investigated in the ultraviolet (UV) erythema test in vivo. 40 volunteers were enrolled in this monocentric, randomized, placebo-controlled double-blind study. The test areas on the back were irradiated with the 1.5 fold minimal erythema dose UV-B. Subsequently, the test areas were treated under occlusion for 47 hours with a lipolotion containing $0.5 \%$ or $1.0 \%$ essential coriander oil. Hydrocortisone $(1.0 \%)$ and betamethasone valerate $(0.1 \%)$ in the vehicle were used as positive controls. The vehicle was used as placebo. The effect of the test substances on the UV-induced erythema was measured photometrically after 48 hours. Additionally, the skin tolerance of the test preparations was assessed on nonirradiated skin. Compared to placebo, the lipolotion with $0.5 \%$ coriander oil significantly reduced the UV induced erythema, but it was not as effective as hydrocortisone. The skin tolerance of both coriander oil concentrations was excellent [132].

A randomized, placebo-controlled study was carried out on 40 healthy subjects to determine the antiinflammatory effects of many plants. Test areas on the upper back were irradiated with the 1.5 fold UV-B minimal erythema dose (MED). Formulations of Aloe vera, Chamomilla recutita, Hamamelis virginiana, Melissa 
officinalis, Mentha arvensis, Melaleuca alternifolia, Coriandrum sativum, as well as $1 \%$ hydrocortisone acetate and $0.1 \%$ betamethasone valerate as positive controls and unguentum leniens as vehicle control were applied under occlusion on the irradiated areas and on non-irradiated area on the contralateral side. Photometric assessment of the erythema was performed before the application of the substances, at $24 \mathrm{~h}$ and at $48 \mathrm{~h}$. Aloe vera, Chamomilla recutita, Melissa officinalis, Melaleuca alternifolia and Coriandrum sativum showed an antiinflammatory effect compared to UV-control and unguentum leniens [133].

Antidiabetic effect:

Administration of coriander seeds (5g/day) to NIDDM patients for 60 days significantly decreased lipid peroxidation, protein oxidation, decreased activity of erythrocyte catalase (CAT), increased serum $\beta$ carotene, vitamin $\mathrm{A}, \mathrm{E}$ and $\mathrm{C}$ in NIDDM diabetics. The treatment was also increased the activity of erythrocyte antioxidant enzyme i.e. glutathione-S-transferase (GST) and reduced glutathione content (GSH) in the treated diabetics [134].

The hypoglycemic effect of Coriandrum sativum was studied clinically in patients with type-2 diabetes mellitus. After assaying fasting plasma and urinary glucose, 10 patients of type-2 diabetes mellitus with no previous medication, 10 patients of type- 2 diabetes mellitus taking oral hypoglycemic agents with history of inadequate control and six control subjects were given low $(2.5 \mathrm{~g}$ tid) and high $(4.5 \mathrm{~g}$ tid) doses of aqueous and alcoholic extracts of Coriandrum sativum for 14 days. On $15^{\text {th }}$ day, blood and urine samples were taken for glucose estimation. Coriandrum sativum has significant hypoglycemic activity in high dose and can be successfully combined with oral hypoglycemic agents in type-2 diabetic patients whose diabetes was not controlled by oral hypoglycemic drug alone [135-136].

The hypoglycemic activity of methanolic extracts of leaves of Coriandrum sativum was evaluated in rats. The methanolic extract showed significant dose dependant decrease in blood glucose level at a dose of 200 and $400 \mathrm{mg} / \mathrm{kg}$. It also decreased the lipid parameters such as total cholesterol, LDL, HDL, VLDL and TG when compared with diabetic control. SGOT and SGPT were reduced dose dependently [137].

Coriander incorporated into the diet $(62.5 \mathrm{~g} / \mathrm{kg})$ and drinking water $(2.5 \mathrm{~g} / \mathrm{l}$, prepared by $15 \mathrm{~min}$ decoction) reduced hyperglycaemia of streptozotocin-diabetic mice. An aqueous extract of coriander $(1 \mathrm{mg} / \mathrm{ml})$ increased 2-deoxyglucose transport (1.6-fold), glucose oxidation (1.4-fold) and incorporation of glucose into glycogen of isolated murine abdominal muscle (1.7-fold) comparable with $10^{-8} \mathrm{M}$-insulin. In acute $20 \mathrm{~min}$ tests, $0.25-10 \mathrm{mg} / \mathrm{ml}$ aqueous extract of coriander evoked a stepwise 1.3-5.7-fold stimulation of insulin secretion from a clonal B-cell line. This effect was abolished by $0.5 \mathrm{mM}$-diazoxide. The effect of extract was potentiated by $16.7 \mathrm{mM}$-glucose and $10 \mathrm{mM}$-L-alanine but not by $1 \mathrm{mM}$-3-isobutyl-1-methylxanthine. Insulin secretion by hyperpolarized B-cells $(16.7 \mathrm{mM}$-glucose, $25 \mathrm{mM}-\mathrm{KCl})$ was further enhanced by the presence of extract. Activity of the extract was found to be heat stable, acetone soluble and unaltered by overnight exposure to acid $(0.1 \mathrm{M}-\mathrm{HCl})$ or dialysis to remove components with molecular mass $<2000$ Da. Activity was reduced by overnight exposure to alkali $(0.1 \mathrm{M}-\mathrm{NaOH})$. Sequential extraction with solvents revealed insulin-releasing activity in hexane and water fractions indicating a possible cumulative effect of more than one extract constituent [138].

Coriandrum sativum (CS) supplementation (1\% and 3\% w/w) to high fat diet (HFD) mice (for 12 weeks) significantly prevented HFD induced increment in body weight gain, food intake, feed efficiency, fasting blood glucose, plasma insulin, fasting insulin resistance index (FIRI), plasma and hepatic triglyceride (TG), total cholesterol (TC), plasma free fatty acid (FFA), adipocyte diameter and surface area along with decrement in adipocyte number. These set of changes were comparable to the rosiglitazone $(0.05 \%)$ supplemented HFD fed mice [139].

The ethanol extract of Coriandrum sativum seeds was investigated for its effects on insulin release from the pancreatic beta cells in streptozotocin-induced diabetic rats. Pancreatic sections of 5 microm were processed for examination of insulin-releasing activity using an immunocytochemistry method. The results showed that administration of the ethanol extract (200 and $250 \mathrm{mg} / \mathrm{kg}$, ip) exhibited a significant reduction in serum glucose. On the other hand, administration of streptozotocin decreased the number of beta cells with insulin secretory activity in comparison with intact rats, but treatment with the coriander seed extract $(200 \mathrm{mg} / \mathrm{kg})$ increased significantly the activity of the beta cells in comparison with the diabetic control rats [140].

The potential hypoglycemic activity of Coriandrum sativum (CS)-extract was investigated after a single oral dose and after daily dosing for 30 days (sub-chronic study) in normal and obese-hyperglycemic-hyperlipidemic $(\mathrm{OHH})$ rats. A single dose of CS-extract or GLB suppressed hyperglycemia in OHH rats, and normoglycemia was achieved at $6 \mathrm{~h}$ post dose; there was no effect on lipids, TG or insulin, but insulin resistance (IR) decreased significantly. The hypoglycemic effect was lower in normal rats. In the subchronic study in OHH rats, the effect of (CS-extract> glibenclamide) regarding reducing plasma glucose ( causing normoglycemia on day 21), increasing insulin and decreasing IR, TC, LDL-cholesterol, and TG. Atherosclerotic index was decreased, while cardioprotective indices were increased by CS-extract, with no effect on body weight, urea or creatinine [141]. 
The antihyperglycaemic properties of the aqueous extract from the leaves and stems of Coriandrum sativum were evaluated in normoglycaemic rats, and on $\alpha$-glucosidase activity from Saccharomyces cerevisiae. Rats were administered with the aqueous extract of the plant at 100,300 and $500 \mathrm{mg} / \mathrm{kg}$, to observe the effect on oral sucrose tolerance test. The aqueous extract exhibited significant antihyperglycaemic activity at the three tested doses. In vitro experiments with $\alpha$-glucosidase exhibited a competitive-type inhibition [142].

The antidiabetic and antioxidant effects of Coriandrum sativum (CS) were studied in alloxan-induced diabetic rats. The extracts of CS in alloxan-induced diabetic rats were found to significantly lower blood glucose levels. Antidiabetic activity of the CS extracts was comparable with the clinically available drug glibenclamide. The levels of serum total cholesterol, triglycerides, and low-density lipoprotein cholesterol were lower in the extracttreated group and high-density lipoprotein cholesterol was higher than the diabetic control rats. The extracts of CS exhibited strong scavenging effect on 2, 2-diphenyl-2-picrylhydrazyl free radical and inhibited lipid peroxidation. The free radical scavenging effect of the extracts was comparable with that of the reference antioxidants. Furthermore, it also showed an improved antioxidant potential as evidenced by decreased lipid peroxidation and a significant increase in the activity of various antioxidant enzymes such as catalase, superoxide dismutase, and glutathione peroxidase in the liver of diabetic rats [50].

\section{Mutagenic and antimutagenic effect:}

The mutagenic effects of Coriandrum sativum extract were evaluated by Ames test. Mutagenicity was present when the Coriandrum sativum extract caused mutagenicity when used in high concentrations in both Salmonella typhimurium TA97 and TA102 strains. Coriandrum sativum extract also reduced the cell survival of human cell lines (WRL-68 and 293Q cells) by inducing apoptosis and necrosis in high concentration. The Coriandrum sativum extract altered the cell cycle; it increased the G1 phase of hepatic cells and reduced the G2 and $\mathrm{M}$ phase in both cell lines in a dose-response manner. The results showed correlation with a reduction in the mitotic index. The extract also induced severe malformations during embryonic development. Exposure of chicken embryos to the Coriandrum sativum extract resulted in a dose-dependent increase of anomalies. The results show that Coriandrum sativum extract reduced the axial skeleton and affected the neural tube, the cardiovascular structures, and the eye [143].

The antimutagenic activity of coriander juice against the mutagenic activity of 4-nitro-ophenylenediamine, m-phenylenediamine and 2-aminofluorene was investigated using the Ames reversion mutagenicity assay (his- to his+) with the S. typhimurium TA98 strain as indicator organism. The plant cell/microbe coincubation assay was used as the activating system for aromatic transformation and plant extract interaction. Aqueous crude coriander juice significantly decreased the mutagenicity of metabolized aromatic amines (AA) in the following order: 2-AF (92.43\%) > m-PDA (87.14\%) > NOP (83.21\%). The chlorophyll content in vegetable juice was monitored and its concentration showed a positive correlation with the detected antimutagenic effect. The concentration of coriander juice (50-1000 microl/coincubation flask) was neither toxic nor mutagenic. The similar shape of the antimutagenic response curves obtained with coriander juice and chlorophyllin (used as a subrogate molecule of chlorophyll) indicated that comparable mechanisms of mutagenic inhibition could be involved [144].

The biochemical effects of coriander seeds on lipid parameters in 1, 2-dimethyl hydrazine (DMH)induced colon cancer were studied in rats. The results showed that the concentrations of cholesterol and cholesterol to phospholipid ratio decreased while the level of phospholipid was increased significantly in the DMH control group compared to the spice administered group. Fecal dry weight, fecal neutral sterols and bile acids showed a sharp increase in the coriander-fed group compared with the DMH administered group [145146].

\section{Anticancer effect:}

Brine shrimp lethality bioassay revealed that coriander $\mathrm{LC}_{50}$ was $2.25 \mathrm{mg} / \mathrm{ml}$ [92]. The anticancer activities of Coriandrum sativum root, leaf and stem, as well as its effect on cancer cell migration, and its protection against DNA damage, with special focus on the roots was evaluated. The ethyl acetate extract of Coriandrum sativum roots showed the highest antiproliferative activity on $\mathrm{MCF}-7$ cells $\left(\mathrm{IC}_{50}=200.0 \pm 2.6 \mu \mathrm{g} / \mathrm{ml}\right)$, had the highest phenolic content and FRAP and DPPH scavenging activities among the extracts. Ethyl acetate extract of Coriandrum sativum root inhibited DNA damage and prevented MCF-7 cell migration induced by $\mathrm{H}_{2} \mathrm{O}_{2}$, suggesting its potential in cancer prevention and metastasis inhibition. The extract exhibited anticancer activity in MCF-7 cells by affecting antioxidant enzymes possibly leading to $\mathrm{H}_{2} \mathrm{O}_{2}$ accumulation, cell cycle arrest at the G2/M phase and apoptotic cell death by the death receptor and mitochondrial apoptotic pathways [147].

The antitumor and immunomodulating activities of aqueous and methanol extracts of Coriandrum sativum (leaf and seed) was investigated in vitro. The aqueous extract of Coriandrum sativum (leaf), caused significant $(\mathrm{P}<0.05) 24,39$ percent L5178Y-R lymphoma cells toxicity at $31.2 \mu \mathrm{g} / \mathrm{ml}$ (MIC), whereas the methanol extract of Coriandrum sativum (seed and leaf) caused 40 and 31 percent cytotoxicity at $7.8,62.5 \mu \mathrm{g} / \mathrm{ml}$ (MICs), 
respectively. In addition, Coriandrum sativum leaf aqueous extract stimulated significant $(\mathrm{P}<0.01) 14$ to 45 percent splenic cells lymphoproliferation at 7.8 to $125 \mu \mathrm{g} / \mathrm{ml}$ respectively. The methanol extracts of Coriandrum sativum leaf extract caused significant $(\mathrm{P}<0.01) 43$ to 59 percent lymphoproliferation at the tested concentrations. Furthermore, Coriandrum sativum aqueous extracts were significantly $(\mathrm{P}<0.01)$ reduce up to $100 \%$ nitric oxide production by LPS-stimulated macrophages [148].

Three different cell lines BMK (kidney), KHOS-2405 (bone), and WRL-68 (liver) were used to determine cytotoxicity. Cells were treated with different Coriandrum sativum (Cilantro) concentrations $(0.125 \%, 0.25 \%$, $0.5 \%, 1 \%, 1.5 \%, 2 \%$ and $2.5 \%$ ), for 24 hours. After this time, cytotoxic studies were performed. An embryotoxicity study was done using fertile chicken eggs (Gallus gallus) inoculating with Coriandrum sativum concentrations $(0.125 \%, 0.25 \%, 0.5 \%, 1 \%, 1.5 \%, 2 \%$ and $2.5 \%)$; incubated for 48 hours and observe them using an electronic microscope to check the effects. The three lines showed decreased proliferation and number of cells proportional to the concentrations. The cell cycle analysis showed that Coriandrum sativum arrested the WRL-68 cells in the (S) phase; the BMK cells were arrested in the G2 and M phase, and the KHOS cells in the G1 phase. Coriandrum sativum produced important morphologic effects on chicken embryos. The use of Coriandrum sativum produces toxicological effects on the embryos only in high doses [149].

\section{Cardiovascular effects:}

Coriander crude extract $(1-30 \mathrm{mg} / \mathrm{ml})$ caused fall in arterial blood pressure of anesthetized animals which partially blocked by atropine. Coriander crude extract produced vasodilatation against phenylephrine and $\mathrm{K}^{+}(80$ $\mathrm{mM}$ )-induced contractions in rabbit aorta and caused cardio-depressant effect in guinea-pig atria. Bioassaydirected fractionation revealed the separation of spasmogenic and spasmolytic components in the aqueous and organic fractions respectively. Furthermore, Coriander crude extract produced diuresis in rats at $1-10 \mathrm{mg} / \mathrm{kg}$ [150].

Aqueous extracts of coriander seeds inhibited the electrically- evoked contractions of spiral strips and tubular segments of isolated central ear artery of rabbit [151]. The water extract of coriander seed had hypotensive effects in rats [152]. The preventive effect of Coriandrum sativum (CS) on cardiac damage was evaluated by isoproterenol induced cardiotoxicity model in male rats. Rats were pretreated with methanolic extract of CS seeds at a dose of 100, 200 or $300 \mathrm{mg} / \mathrm{kg}$ orally for 30 days and they were subsequently administered (sc) with isoproterenol ( $85 \mathrm{mg} / \mathrm{kg}$ body weight) for the last two days. Isoproterenol treated rats showed increased LPO, decreased levels of endogenous antioxidants and ATPases in the cardiac tissue together with increased plasma lipids and markers of cardiac damage. TTC staining showed increased infarct areas while HXE staining showed myofibrillar hypertrophy and disruption. CS (200 and $300 \mathrm{mg} / \mathrm{kg}$ body weight) pretreatment significantly prevented or resisted all these changes. The results showed that methanolic extract of CS is able to prevent myocardial infarction by inhibiting myofibrillar damage. It is also postulated that, the rich polyphenolic content of CS extract was responsible for preventing oxidative damage by effectively scavenging the isoproterenol generated ROS [153].

\section{Gastrointestinal effects:}

In a randomized, double-blinded clinical trial, performed in Isfahan dental school in 2012, a new herbal medicament containing combined extracts from Q. brantii and Coriandrum sativum was formulated in the gel form for subgingival application. Following scaling and root planing (SRP), both herbal and placebo gels were delivered at the experimental and control sites, respectively. Periodontal pocket depth, clinical attachment level, papilla bleeding index, and plaque index were measured at baseline, 1 month and 3 months later. Both groups indicated statistically significant improvements in the periodontal indices $(\mathrm{p}<0.05)$ [154].

The effect of coriander pretreatment on gastric mucosal injuries caused by $\mathrm{NaCl}, \mathrm{NaOH}$, ethanol, indomethacin and pylorus ligation accumulated gastric acid secretions was investigated in rats. Pretreatment at oral doses of 250 and $500 \mathrm{mg} / \mathrm{kg}$, was found to provide a dose-dependent protection against the (i) ulcerogenic effects of different necrotizing agents; (ii) ethanol-induced histopathological lesions; (iii) pylorus ligated accumulation of gastric acid secretions and ethanol related decrease of nonprotein sulfhydryl groups (NP-SH). Results of gastric mucus and indomethacin-induced ulcers demonstrated that the gastro protective activity of Coriander might not be mediated by gastric mucus and/or endogenous stimulation of prostaglandins. The authors suggested that the protective effect against ethanol-induced damage of the gastric tissue might be related to the free-radical scavenging property of different antioxidant constituents (linanool, flavonoids, coumarins, catechins, terpenes and polyphenolic compounds) present in coriander. The inhibition of ulcers might be due to formation of a protective layer of either one or more of these compounds by hydrophobic interactions [155].

The effect of selected indigenous medicinal plants of Pakistan was evaluated on the secretion of interleukin- 8 (IL-8) and generation of reactive oxygen species (ROS) to rationalize their medicinal use and to examine the anti-inflammatory and cytoprotective effects in gastric epithelial cells. AGS cells and clinically isolated 
Helicobacter pylori strain (193C) were employed for co-culture experiments. Coriandrum sativum, demonstrated significant suppression of ROS from Helicobacter pylori-infected cells $(p<0.01)$ [156].

The efficacy of Coriandrum sativum on gut modulation was studied, coriander crude extract was evaluated through in vitro and in vivo techniques. Coriander crude extract caused atropine sensitive stimulatory effect in isolated guinea-pig ileum and rabbit jejunum preparations $(0.1-10 \mathrm{mg} / \mathrm{ml})$. It exhibited relaxation against both spontaneous and high $\mathrm{K}^{+}(80 \mathrm{mM})$-induced contractions as well as shifted the $\mathrm{Ca}^{2+}$ concentration-response curves to right, similar to that caused by verapamil. Bioassay-directed fractionation revealed the separation of spasmogenic and spasmolytic components in the aqueous and organic fractions, respectively [150].

The effect of Coriandrum sativum hydroalcoholic extract was investigated on food intake in rats. It was given as 50,100 or $150 \mathrm{mg} / \mathrm{kg}$ for 7 days. The daily amount of the food eaten by each rat was measured for 10 days. The amount of energy intake of each rat was also calculated for 7 days during the intervention. The difference in energy intake was calculated, and compared between groups. There was no significant change in energy intake between control and vehicle groups. The change in energy intake after treatment by 100 and $150 \mathrm{mg} / \mathrm{kg}$ of the extract was significantly higher than other groups [157].

\section{Hepatoprotective effect:}

The radio protective ability of Coriandrum sativum seeds against whole body gamma irradiation was studied in rats. Coriander aqueous extract group (CE) rats received the aqueous extract $300 \mathrm{mg} / \mathrm{kg} \mathrm{bw} /$ day for 42 days. Irradiated group: rats were subjected to whole body gamma irradiation at dose of 4 Gy delivered as a single exposure dose. In combined treatment group, rats received orally CE (300 mg/ kg bw/ day) for 42 days, at day 35 of $\mathrm{CE}$ treatment, the rats were irradiated at dose level of $4 \mathrm{~Gy}$. The animals exposed to gamma radiation showed a significant increase in serum aspartate transaminase, alanine transaminase, alkaline phosphatase, lactate dehydrogenase, urea, creatinine, total cholesterol, triglycerides, low density lipoprotein cholesterol and tissue thiobarbituric acid reactive substance. Gamma irradiation caused significant decrease in serum total protein, albumin and high density lipoprotein cholesterol. A decrease of liver and kidney reduced glutathione content, superoxides dismutase and catalase activities were reported. Treatment of rats with CE significantly reduced the radiation-induced serum biochemical disorders which was associated with significant amelioration in the oxidant antioxidant status of liver and kidney tissues [158]. The administration of paracetamol caused a significant increase in plasma alanine amino transferase, aspartate amino transferase, alkaline phosphates, gamma glutamyl transferase, bilirubin, urea and creatinine with significant decrease in plasma total proteins, albumin and some antioxidant biomarkers (plasma total antioxidant capacity, catalase and glutathione peroxidase) compared to normal rates. Statistical analysis indicated that rats which supplemented with aqueous extract of Coriandrum sativum and then administrated paracetamol showed significant improvement in all biochemical parameters, which become near to control, the results were confirmed by histopathological examination of the liver tissue of control and treated animals [55].

The antioxidant activity of Coriandrum sativum was evaluated in $\mathrm{CCl}_{4}$ treated oxidative stress in rats. $\mathrm{CCl}_{4}$ injection induced oxidative stress by a significant rise in serum marker enzymes and thiobarbituric acid reactive substances (TBARS) along with the reduction of antioxidant enzymes. In serum, the activities of enzymes, ALP, ACP and protein and bilirubin were evaluated. Pretreatment of rats with different doses of plant extract (100 and $200 \mathrm{mg} / \mathrm{kg}$ ) significantly lowered SGOT, SGPT and TBARS levels against $\mathrm{CCl}_{4}$ treated rats. Hepatic enzymes like SOD, CAT, GPx were significantly increased by treatment with plant extract against $\mathrm{CCl}_{4}$ treated rats. Histopathological examinations showed extensive liver injuries, characterized by extensive hepatocellular degeneration/necrosis, inflammatory cell infiltration, congestion, and sinusoidal dilatation in $\mathrm{CCl}_{4}$ trated rats. Oral administration of the leaf extract at a dose of $200 \mathrm{mg} / \mathrm{kg}$ bw significantly reduced the histological effects induced by $\mathrm{CCl}_{4}$. The activity of leaf extract at the dose of $200 \mathrm{mg} / \mathrm{kg}$ was comparable to the standard drug, silymarin [159].

The hepatoprotective activity of Coriandrum sativum against carbon tetrachloride was studied, with estimation of serum glutamyl oxaloacetic acid transaminase, serum glutamyl pyruvate transaminase, alkaine phosphatase and bilirubin. Coriandrum sativum possessed hepatoprotection by reducing the liver weight, activities of SGOT, SGPT, and ALP, and direct bilirubin of $\mathrm{CCl}_{4}$ intoxicated animals. These results were confermied be histological effects, administration of Coriandrum sativum extract at $300 \mathrm{mg} / \mathrm{kg}$ dose resulted in disappearance of fatty deposit, ballooning degeneration and necrosis [49].

Essential oils of Coriandrum sativum were assayed for their in vitro and in vivo antioxidant activity and hepatoprotective effect against carbon tetrachloride damage. The in vitro antioxidant activity was evaluated as a free radical scavenging capacity (RSC), measured as scavenging activity of the essential oils on 2,2-diphenyl-1picrylhydrazyl (DPPH) and OH radicals and effects on lipid peroxidation (LP) in two systems of induction. Liver biochemical parameters were determined in animals pretreated with essential oils and later intoxicated with $\mathrm{CCl}_{4}$ to assess in vivo hepatoprotective effect. The essential oils were able to reduce the stable DPPH in a dosedependent manner and to neutralize $\mathrm{H}_{2} \mathrm{O}_{2}$, with $\mathrm{IC}_{50}$ values of $4.05 \mathrm{microl} / \mathrm{ml}[160]$. 
The effect of coriander seed powder (CSP) on dimethyl hydrazine (DMH)-induced oxidative stress and toxicity in rats was investigated. Rats were maintained on the treatments for 12 weeks. The results revealed that DMH administration lead to an increase in hepatic lipid peroxidation associated with reduction in levels of glutathione (GSH), activity of superoxide dismutase (SOD), catalase, and glucose-6-phosphate dehydrogenase. The coadministration of CSP $10 \%$ and DMH diminished the hepatic malondialdehyde (MDA) significantly as compared to DMH-alone administered rats. The intake of coriander seeds at $10 \%$ level also enhanced the hepatic GSH-redox system by elevating GSH-Px, GSSGR, and GST activities. The DMH-induced decline in SOD and catalase activities was brought to normal by $10 \%$ CSP. The coadministration of CSP and the DMH produced a significant reduction in MDA and enhancement in catalase activity as compared to control. Coriander powder at $5 \%$ and $10 \%$ levels produced a significant rise in colonic catalase and GSH-Px. The coriander seeds produced significant beneficial effects by reducing the DMH-induced oxidative stress and enhancing the tissue levels of antioxidant/detoxification agent in tissues [161].

\section{Deodorizing effect}

The leaves of Coriandrum sativum exhibited a strong deodorizing effect against porcine internal organs (large intestine). The effective deodorizing compounds of coriander were identified by separating the volatile component of coriander, testing the effectiveness of each fraction against the offensive odor of porcine large intestine, and then identifying the compounds by GC-MS. The volatile component of coriander was first separated into six fractions (A-F) by preparative gas chromatography, and the deodorizing activity of each of these fractions against the offensive odor was measured. Fraction D, which showed the strongest deodorizing effect, was then separated into 12 subfractions by preparative GC. The deodorant activity of each subfraction was evaluated, and the deodorant compounds were identified by GC-MS. (E,E)-2,4-undecadienal was the most effective deodorizing compound. The deodorizing activity of (E,E)-2,4-undecadienal on the porcine large intestine increased with concentration, reaching almost complete deodorizing ability at $10 \mathrm{ppb}$ [162].

\section{Detoxification effect}

The preventive effect of ethanol extract of Coriandrum sativum on lead deposition was investigated in male ICR mice given lead (1000 ppm) as lead acetate trihydrate in drinking water for 32 days. Administration of Coriandrum sativum to mice by gastric intubation was performed for 25 days from day 7 after the start of lead exposure up to the end of the experiment. The mice were then sacrificed for comparison of lead distribution. The lead reached its highest concentration in the femur but localized lead deposition in the femur was significantly decreased by meso-2,3-dimercaptosuccinic acid (DMSA), a chelating agent used as a positive control to validate the experimental model. Administration of Coriandrum sativum also significantly decreased lead deposition in the femur and severe lead-induced injury in the kidneys. In addition, urinary excretion of delta-aminolevulinic acid (ALA) which was known to increase with lead intake was significantly decreased after administration of Coriandrum sativum. The $\mathrm{MeOH}$ extract of Coriandrum sativum also reduced lead-induced inhibition of deltaaminolevulinic acid dehydratase (ALAD) activity in vitro [163].

The protective effect of Coriandrum sativum in lead intoxication was studied mice. Oxidative stress was induced in mice by a daily dose of lead nitrate $(40 \mathrm{mg} / \mathrm{kg}$ bw by oral gavage) for seven days. From day eight, experimental animals received an oral dose of coriander extracts (aqueous extract 300 and $600 \mathrm{mg} / \mathrm{kg}$ bw; ethanolic extract 250 and $500 \mathrm{mg} / \mathrm{kg} \mathrm{bw}$ ) along with lead nitrate daily for 40 days. The coriander supplementation to intoxicated mice, protected the weights of experimental animals as compared to lead nitrate exposed untreated animals. Ingestion of $\mathrm{Pb}\left(\mathrm{NO}_{3}\right)_{2}$ was significantly decreased $\mathrm{RBC}$ count, WBC count, $\mathrm{Hb}$ level and serum total protein contents in the lead nitrate treated mice. But, serum alanine transaminase, aspartate aminotransferase, creatinine and cholesterol level were significantly increased after implication of this metal. However, oral administration of Coriandrum sativum to lead treated mice led to marked improvement in both hematological and serum biochemical changes. A decrease in viability of neutrophiles, phagocytic index, immunoglobulin level and plaque count were the salient features observed in lead exposed animals. Oral administration of coriander extracts to $\mathrm{Pb}\left(\mathrm{NO}_{3}\right)_{2}$ treated groups attenuated the deranged parameters to some extent [164].

The efficacy of Coriandrum sativum in reducing lead-induced changes in testis was evaluated in mice. Animal exposed to lead nitrate showed significant decrease in testicular SOD, CAT, GSH, and total protein levels. This was accompanied by simultaneous increase in the activities of LPO, AST, ALT, ACP, ALP, and cholesterol level. Serum testosterone level and sperm density were suppressed in lead-treated group compared with the control. These influences of lead were prevented by concurrent daily administration of Coriandrum sativum extracts to some extent. Treating albino mice with lead-induced various histological changes in the testis, while the treatment with coriander led to an improvement in the histological testis picture [165].

The protective activity of the hydroalcoholic extract of Coriandrum sativum seed against lead-induced oxidative stress was studied in rats. Male rats were given $1,000 \mathrm{mg} / \mathrm{L}$ lead acetate for 4 weeks, Coriandrum sativum 
treatment was given as 250 and $500 \mathrm{mg} / \mathrm{kg}$ bw/day for seven consecutive days after 4 weeks of lead exposure. A significant $(\mathrm{p}<0.05)$ increase in reactive oxygen species, lipid peroxidation products, and total protein carbonyl content levels was observed in exposed rat brain regions, while delta-amino levulinic acid dehydratase showed a decrease indicating lead-induced oxidative stress. Treatment with the hydroalcoholic seed extract of Coriandrum sativum resulted in a tissue-specific amelioration of oxidative stress produced by lead [166].

The effect of Coriandrum sativum was studied against lead nitrate induced toxicity in mice. Oxidative stress was induced in mice by a daily dose of lead nitrate $(40 \mathrm{mg} / \mathrm{kg}$ bw by oral gavage) for seven days. From day eight, after lead nitrate treatment, experimental animals received an oral dose of coriander extracts (aqueous extract $300 \mathrm{mg} / \mathrm{kg}$ body weight and $600 \mathrm{mg} / \mathrm{kg}$ bw, ethanolic extract 250 and $500 \mathrm{mg} / \mathrm{kg} \mathrm{bw}$ ) daily. The effect of these treatments in influencing the lead induced changes on hepatic and renal oxidative stress and biochemical changes along with histopathological alterations in soft tissues were studied. The results showed significant increase in liver and kidney LPO levels in animals treated with lead nitrate while the effect was attenuated by the plant extracts. Also, lead caused a significant decrease in antioxidant enzyme activity and this effect was reversed in groups treated with plant extract. Treatment with coriander significantly reduced the adverse effects related to biochemical parameters altered in animals treated with lead and to hepatic and renal oxidative stress. Oral administration of coriander to lead treated mice attenuated the deranged histopathological changes to some extent [167].

\section{Diuretic effect:}

The acute diuretic activity of aqueous extract of the seed of Coriandrum sativum was evaluated in rats. The aqueous extract of coriander seed was administered by continuous intravenous infusion (120 min) at two doses (40 and $100 \mathrm{mg} / \mathrm{kg}$ ) to anesthetized Wistar rats. Furosemide $(10 \mathrm{mg} / \mathrm{kg})$, a standard diuretic was used as the reference drug. Excretion of water and electrolytes (sodium, potassium and chloride) in urine, and glomerular filtration rate (equal to creatinine clearance) were determined. The crude aqueous extract of coriander seeds increased diuresis, excretion of electrolytes, and glomerular filtration rate in a dose-dependent way. Furosemide was more potent as a diuretic and saluretic. The authors concluded that the mechanism of action of the plant extract appears to be similar to that of furosemide [168].

\section{Dermatological effect:}

Coriandrum sativum ethanol extract (CSE) showed a protective effects against UVB-induced skin photoaging in normal human dermal fibroblasts (NHDF) in vitro and in the skin of hairless mice in vivo. The cellular levels of procollagen type I and MMP-1 were determined using ELISA in NHDF cells after UVB irradiation. NHDF cells that were treated with CSE after UVB irradiation exhibited higher procollagen type I production and lower levels of MMP-1 than untreated cells. The activity of transcription factor activator protein1 (AP-1) was also inhibited by CSE treatment. CSE-treated mice had thinner epidermal layers and denser dermal collagen fibers than untreated mice. On a molecular level, it was further confirmed that CSE-treated mice had lower MMP-1 levels and higher procollagen type I levels than untreated mice [169].

The protective effect of Coriandrum sativum (CS) against 2,4-dinitrochlorobenzene-induced CD-like skin lesions was studied in mice. CS, at doses of 0.5-1\%, applied to the dorsal skin inhibited the development of CD-like skin lesions. Moreover, the Th2-mediated inflammatory cytokines, immunoglobulin E, tumor necrosis factor- $\alpha$, interferon- $\gamma$, interleukin (IL)-1, IL-4, and IL-13, were significantly reduced. In addition, CS increased the levels of total glutathione and heme oxygenase-1 protein. Thus, CS inhibited the development of CD-like skin lesions in mice by regulating immune mediators and may be an effective alternative therapy for contact diseases [170].

The protective effect of a standardized coriander (CS) leaf extract was studied against oxidative stress in human HaCaT keratinocytes. CS significantly and dose-dependently protected cells against reduced cell viability caused by $\mathrm{H}_{2} \mathrm{O}_{2}$-induced damage, as assessed by 3-(4,5-dimethylthiazol-2-yl)-2,5-diphenyltetrazolium bromide assay. Other assays demonstrated that CS protected HaCaT cells by increasing the levels of glutathione and activities of oxidative defense enzymes, such as superoxide dismutase and catalase. Moreover, it increased the expression of activated Nrf2, which plays a crucial role in protecting skin cells against oxidative stress [171].

\section{Effect on fertility:}

Effect of the aqueous extract of fresh coriander (Coriandrum sativum) seeds has been studied on female fertility in rats including the effects on oestrus cycle, implantation, foetal loss, abortion, teratogenicity and serum progesterone levels on days 5, 12 and 20 of the pregnancy. The extract at doses of 250 and $500 \mathrm{mg} / \mathrm{kg}$ orally produced a dose-dependent significant anti-implantation effect, but did not produce complete infertility. Treatment of animals during day- 8 to day-12 and day-12 to day-20 of the pregnancy did not produce any significant abortifacient activity. There was no significant change in the weight and length of the foetuses delivered by rats treated with the extract and no abnormalities were seen in the organs of the offsprings. The 
extracts produced a significant decrease in serum progesterone levels on day-5 of pregnancy which may be responsible for its anti-implantation effect [172].

\section{Contra-indications and side effects}

The median lethal dose $\left(\mathrm{LD}_{50}\right)$ of Coriandrum sativum essential oil was determined as $2.257 \mathrm{ml} / \mathrm{kgin}$ mice [173]. The maximum non-fatal dose of the decoction and maceration extracts was $0.5 \mathrm{~g} / \mathrm{kg}$ and $5 \mathrm{~g} / \mathrm{kg}$, and the $\mathrm{LD}_{50}$ values of the decoction and maceration extracts were $0.78 \mathrm{~g} / \mathrm{kg}$ and $8.11 \mathrm{~g} / \mathrm{kg}$, respectively [77].

Acute toxicity studies performed on ethanolic extract of Coriandrum sativum leaves did not show any signs and symptoms of toxicity and mortality up to $2000 \mathrm{mg} / \mathrm{kg}$ dose, except centrally induced depression evidenced by alertness, motor activity and increased urination and defecation [49].

\section{CONCLUSION}

This review discusses the chemical constituent, pharmacological and therapeutic effects of Coriandrum sativum. According to the wide range of pharmacological activities, Coriandrum sativum should be considered as a promising source of many drugs because of its safety and effectiveness.

\section{REFERENCES}

[1] Al-Snafi AE. The pharmacology of Crocus sativus- A review. IOSR Journal of Pharmacy 2016; 6(6): 838.

[2] Al-Snafi AE. The chemical constituents and therapeutic importance of Cressa cretica- A review . IOSR Journal of Pharmacy 2016; 6(6): 39-46.

[3] Al-Snafi AE. The Pharmacological and therapeutic importance of Cordia myxa- A review. IOSR Journal of Pharmacy 2016; 6(6): 47-57.

[4] Al-Snafi AE. The contents and pharmacological importance of Corchorus capsularis- A review. IOSR Journal of Pharmacy 2016; 6(6): 58-63.

[5] Al-Snafi AE. The chemical constituents and pharmacological effects of Convolvulus arvensis and Convolvulus scammonia- A review. IOSR Journal of Pharmacy 2016; 6(6): 64-75.

[6] Al-Snafi AE. Medicinal plants possessed anti-inflammatory antipyretic and analgesic activities (part 2)plant based review. Sch Acad J Pharm 2016; 5(5): 142-158.

[7] Al-Snafi AE. Medicinal plants affected reproductive systems (part 2) - plant based review. Sch Acad J Pharm 2016; 5(5): 159-174.

[8] Al-Snafi AE. Medicinal plants with anticancer effects (part 2)- plant based review. Sch Acad J Pharm 2016; 5(5): 175-193.

[9] Al-Snafi AE. Antiparasitic, antiprotozoal, molluscicidal and insecticidal activity of medicinal plants (part 2) - plant based review. Sch Acad J Pharm 2016; 5(5): 194-207.

[10] Al-Snafi AE. Chemical constituents and pharmacological effects of Cynodon dactylon- A review. IOSR Journal Of Pharmacy 2016; 6(7): 17-31.

[11] Al-Snafi AE. A review on Cyperus rotundus A potential medicinal plant. IOSR Journal Of Pharmacy 2016; 6(7): 32-48.

[12] Al-Snafi AE. Medicinal plants with antidiabetic effects (part 2): plant based review. IOSR Journal Of Pharmacy 2016; 6(7): 49-61.

[13] Al-Snafi AE. Medicinal plants with antioxidant and free radical scavenging effects (part 2): plant based review. IOSR Journal Of Pharmacy 2016; 6(7): 62-82.

[14] Al-Snafi AE. Therapeutic properties of medicinal plants: a review of plants with anti-inflammatory, antipyretic and analgesic activity (part 1). Int J of Pharmacy 2015; 5(3): 125-147.

[15] Al-Snafi AE. Therapeutic properties of medicinal plants: a review of plants with cardiovascular effects (part 1). Int J of Pharmacology \& Toxicology 2015; 5(3): 163-176.

[16] Al-Snafi AE. Therapeutic properties of medicinal plants: a review of medicinal plants with central nervous effects (part 1). Int J of Pharmacology \& Toxicology 2015; 5(3): 177-192.

[17] Al-Snafi AE. Clinically tested medicinal plant: A review (Part 1). SMU Medical Journal 2016; 3(1): 99128.

[18] Al-Snafi AE. Medical importance of Antemis nobilis ( Chamaemelum nobilis)- A review. Asian Journal of Pharmaceutical Science \& Technology 2016; 6(2): 89-95.

[19] Al-Snafi. AE. Adonis aestivalis: pharmacological and toxicological activities- A revew. Asian Journal of Pharmaceutical Science \& Technology 2016; 6(2): 96-102.

[20] Al-Snafi AE. Chemical constituents and pharmacological importance of Agropyron repens - A review. Research Journal of Pharmacology and Toxicology 2015; 1 (2): 37-41.

[21] Al-snafi AE. Chemical constituents and pharmacological effects of Citrullus colocynthis - A review. IOSR Journal Of Pharmacy 2016; 6(3): 57-67. 
[22] Al-Snafi AE Medical importance of Cichorium intybus - A review IOSR Journal of Pharmacy 2016; 6(3): 41-56.

[23] Al-Snafi AE. Pharmacological importance of Clitoria ternatea - A review IOSR Journal of Pharmacy 2016; 6(3): 68-83.

[24] Al-Snafi AE. The medical Importance of Cicer arietinum - A review IOSR Journal of Pharmacy 2016; 6(3): $29-40$

[25] Al-Snafi AE. The pharmacological Importance of Antirrhinum majus - A review. Asian J of Pharm Sci \& Tech 2015; 5(4): 313-320.

[26] Al-Snafi AE. Chemical constituents and pharmacological effects of Astragalus hamosus and Astragalus tribuloides grown in Iraq. Asian J of Pharm Sci \& Tech 2015; 5(4): 321-328.

[27] Al-Snafi AE. The pharmacological activities of Cuminum cyminum - A review. IOSR Journal of Pharmacy 2016; 6(6): 46-65.

[28] Al-Snafi AE. Medical importance of Cupressus sempervirens- A review. IOSR Journal of Pharmacy 2016; 6(6): 66-76.

[29] Al-Snafi AE. The contents and pharmacology of Crotalaria juncea- A review. IOSR Journal of Pharmacy 2016; 6(6): 77-86.

[30] Al-Snafi AE. The medical importance of Cydonia oblonga- A review. IOSR Journal of Pharmacy 2016; 6(6): 87-99.

[31] The plant list, A working list of all plant species, Coriandrum sativum http://www.theplantlist.org/tpl1.1/record/kew-2737546 (2013).

[32] Bhatnagar SS. (ed.), Coriandrum sativum Linn. (Umbelliferae), The wealth of India. A dictionary of Indian raw materials and industrial products, raw materials. Council of Scientific and Industrial Research, New Delhi 1950;2: 347-350.

[33] Samba Murty AVSS and Subrahmanyam NS. A textbook of economic botany. Wiley Eastern Limited, New Delhi 1989: 416-419.

[34] Anju V, Pandeya SN, Yadav SK, Singh S and Soni P. A Review on Coriandrum sativum (Linn.): An Ayurvedic medicinal herb of happiness. JAPHR 2011; 1(3):28-48.

[35] USDA, ARS, National Genetic Resources Program. Germplasm Resources Information Network(GRIN). National Germplasm Resources Laboratory, Beltsville, Maryland. URL: http://www.arsgrin.gov.4/cgi-bin/npgs/html/taxon.pl? 11523 (22 July 2015).

[36] -Small E. Culinary herbs. NRC Research Press, Ottawa 1997:219-225.

[37] The University of Queensland. Special edition of environmental weeds of Australia for biosecurity Queensland, $\quad$ http://keyserver.lucidcentral.org/weeds/data/080c0106-040c-4508-83000b0a06060e01/media/Html/Conium_maculatum.htm (2011).

[38] -Randall RP. A global compendium of weeds. Second edition. Department of Agriculture and Food, Western Australia 2012.

[39] Lamp C and Collet F. Field guide to weeds in Australia. Inkata Press, Melbourne, Victoria 1989.

[40] Coskuner Y and Karababa E. Physical properties of coriander seeds (Coriandrum sativum L.). J Food Engin 2007; 80(2):408-416.

[41] Craker LE and Simon JE. Herb spices and medicinal plant, vol.3, CBS Publishers and Distributors, New Delhi 2002.

[42] Kirtikar KR and Basu BD. Indian medical plants, second edition, vol.2, International Book Distributers, Dehradun, India 1999.

[43] Kokate CK, Purohit AP and Gokhale SB. Pharmacognosy, 39 ${ }^{\text {th }}$ edition, Nirali Prakashan, Pune 2007.

[44] The United States Pharmacopoeia, NF 22- The National formulary, Asian edition, United States Pharmacopial convention Inc 2004.

[45] Shivanand P. Coriandrum sativum: A biological description and its uses in the treatment of various diseases. IJPLS 2010; 1(3):119-126.

[46] 46-Bhat S, Kaushal P, Kaur M and Sharma HK. Coriander (Coriandrum sativum L.): Processing, nutritional and functional aspects. African Journal of Plant Science 2014; 8(1): 25-33.

[47] 47-Axel D. Promoting the conservation and use of underutilized and neglected crops: Coriander (Coriandrum sativum L). $1^{\text {st }}$ ed., International Plant Genetic Resources Institute IPGRI, Italy 1996.

[48] Chauhan KPK, Jaryal M, Kumari K and Singh M. Phytochemical and in vitro antioxidant potential of aqueous leaf extracts of Brassica juncea and Coriandrum sativum. IJPSR 2012; 3(8): 2862-2865.

[49] Pandey A, Bigoniya P, Raj V, and Patel AA. Pharmacological screening of Coriandrum sativum Linn. for hepatoprotective activity. J Pharm Bioallied Sci 2011; 3(3): 435-441.

[50] Sreelatha S and Inbavalli R. Antioxidant, antihyperglycemic, and antihyperlipidemic effects of Coriandrum sativum leaf and stem in alloxan-induced diabetic rats. J Food Sci 2012;77(7):T119-123. 
[51] Parthasarathy VA, Chempakam B and Zachariah TJ. Coriander: In Chemistry of spices. CAB International, UK 2008: 190-206.

[52] Ramezani S, Rahamanian M, Jahanbin R, Mohajeri F, Rezaei MR and Solaimani B. Diurnal changes essential oil content of Coriander (Coriandrum sativum L.) aerial parts from Iran. Res J Biol Sci 2009; 4(3):277-281.

[53] Chung IM, Ahmad A, Kim EH, Kim SH, Jung WS, Kim JH, Nayeem A and Nagella P. Immunotoxicity activity from the essential oils of coriander (Coriandrum sativum) seeds. Immunopharmacol Immunotoxicol 2012; 34(3):499-503.

[54] Ciocarlan $\mathrm{N}$ and Zarbock-Udrea S. Contributions to the studies on the essential oils isolated from Coriandrum sativum L. and Foeniculum vulgare Mill. Journal of Academy of Sciences of Moldova Life Sciences 2015; 2(326): 55-60.

[55] Ramadan MM and Abd Algader NNE. Chemopreventive effect of Coriandrum sativum fruits on hepatic toxicity in male rats. World Journal of Medical Sciences 2013; 8 (4): 322-333.

[56] Sourmaghi MH, Kiaee G, Golfakhrabadi F, Jamalifar H and Khanavi M. Comparison of essential oil composition and antimicrobial activity of Coriandrum sativum L. extracted by hydrodistillation and microwave-assisted hydrodistillation. J Food Sci Technol 2015;52(4):2452-2457.

[57] Ramadan MF and Mörsel JT. Oil composition of coriander (Coriandrum sativum L.) fruit-seeds. Eur Food Res Technol 2002; 215:204-209.

[58] Chung IM, Ahmad A, Kim SJ, Naik PM and Nagella P. Composition of the essential oil constituents from leaves and stems of Korean Coriandrum sativum and their immunotoxicity activity on the Aedes aegypti L. Immunopharmacol Immunotoxicol 2012;34(1):152-156.

[59] Bhuiyan NI, Begum J and Sultana M. Chemical composition of leaf and seed essential oil of Coriandrum sativum L. from Bangladesh. Bangladesh J Pharmacol 2009; 4: 150-153.

[60] Baba K, Xiao YQ, Taniguchi M, Ohishi H and Kozawa M. Isocoumarins from Coriandrum sativum. Phytochemistry 1991; 30(12): 4143-4146.

[61] 61-Melo EA, Filho JM and Guerra NB. Characterization of antioxidant compounds in aqueous 6oriander extract (Coriandrum sativum L.). Food Sci Technol 2005; 38(1): 15-19.

[62] Rajeshwari CU and Andallu B. Reverse phase HPLC for the detection of flavonoids in the ethanolic extract of Coriandrum sativum L seeds. International Journal of Basic and Applied Sciences 2012; 1(1): 21-26.

[63] Deepa B and Anuradha CV. Antioxidant potential of Coriandrum sativum L. seed extract. Indian J Exp Biol 2011;49(1):30-38.

[64] Harsha SN and Anilakumar KR. In vitro free radical scavenging and DNA damage protective property of Coriandrum sativum L. leaves extract. J Food Sci Technol 2014;51(8):1533-1539.

[65] Pathan AR, Kothawade KA and Logade MN. Anxiolytic and analgesic effect of seeds of Coriandrum sativum Linn. IJRPC 2011; 1(4): 1087-1099.

[66] Latha K, Rammohan B, Sunanda BP, Maheswari MS and Mohan SK. Evaluation of anxiolytic activity of aqueous extract of Coriandrum sativum Linn in mice: A preliminary experimental study. Pharmacognosy Res 2015; 7(Suppl 1):S47-51.

[67] Mahendra $\mathrm{P}$ and Bisht S. Anti-anxiety activity of Coriandrum sativum assessed using different experimental anxiety models. Indian J Pharmacol 2011; 43(5): 574-577.

[68] Emamghoreishi M, Khasaki M and Aazam MF. Coriandrum sativum has anxiolytic and potentially sedative and muscle relaxant effects. Mol Cancer Ther 2007; 6(3): 1013-1021.

[69] Emamghoreishi M, Khasaki M and Aazam MF. Coriandrum sativum: evaluation of its anxiolytic effect in the elevated plus-maze. J Ethnopharmacol 2005; 96(3): 365-370.

[70] Harsha SN and Anilakumar KR. Effects of Coriandrum sativum extract on exploratory behaviour pattern and locomotor activity in mice: An experimental study. IJGB 2012; 6(2):157-162.

[71] -Mani V, Parle M, Ramasamy K and Abdul Majeed AB. Reversal of memory deficits by Coriandrum sativum leaves in mice. J Sci Food Agric 2011;91(1):186-192.

[72] Mani V and Parle M. Memory- enhancing activity of Coriandrum sativum in rats. Pharmacologyonline 2009; 2: 827-839.

[73] Sudha K, Deepak G, Sushant K, Vipul P and Nilofer N. Study of antidepressant like effect of Coriandrum sativum and involvement of monoaminonergic and Gabanergic system. IJRAP 2011; 2: 267270.

[74] Emamghoreishi $M$ and Heidari-Hamedani G. Sedative-hypnotic activity of extracts and essential oil of coriander seeds. Iran J Med Sci March 2006; 31(1): 22-27.

[75] Rakhshandeh H, Sadeghnia HR and Ghorbani A. Sleep-prolonging effect of Coriandrum sativum hydroalcoholic extract in mice. Nat Prod Res 2012; 26(22): 2095-2098. 
[76] Karami R, Hosseini M, Mohammadpour T, Ghorbani A, Sadeghnia HR, Rakhshandeh H, Vafaee F and Esmaeilizadeh M. Effects of hydroalcoholic extract of Coriandrum sativum on oxidative damage in pentylenetetrazole-induced seizures in rats. Iran J Neurol 2015;14(2):59-66.

[77] Hosseinzadeh H and Madanifard M. Anticonvulsant effects of Coriandrum sativum L. seed extracts in mice. Iranian Journal of pharmacy 2005; 3: 1-4.

[78] Cioanca O, Hritcu L, Mihasan M and Hancianu M. Cognitive-enhancing and antioxidant activities of inhaled coriander volatile oil in amyloid $\beta(1-42)$ rat model of Alzheimer's disease. Physiol Behav 2013;120:193-202.

[79] Zargar-Nattaj SS, Tayyebi P, Zangoori V, Moghadamnia Y, Roodgari H, Jorsaraei SG and Moghadamnia AA. The effect of Coriandrum sativum seed extract on the learning of newborn mice by electric shock: interaction with caffeine and diazepam. Psychol Res Behav Manag 2011; 4:13-19.

[80] Mohan M, Yarlagadda S and Chintala S. Effect of ethanolic extract of Coriandrum sativum L on tacrine induced orofacial dyskinesia. Indian J Exp Biol 2015; 53(5):292-296.

[81] Vekaria RH, Patel MN, Bhalodiya PN, Patel V, Desai TR and Tirgar PR. Evaluation of neuroprotective effect of Coriandrum sativum Linn. against ischemic - reperfusion insult in brain. International Journal of Phytopharmacology 2012; 3(2): 186-193.

[82] Ghorbani A, Rakhshandeh H, Asadpour E and Sadeghnia HR. Effects of Coriandrum sativum extracts on glucose/serum deprivationinduced neuronal cell death. Avicenna Journal of Phytomedicine 2012; 2(1): 49.

[83] Oudah IM and Ali YH. Evaluation of aqueous and ethanolic extraction for Coriander seeds, leaves and stems and studying their antibacterial activity. Iraqi Sci J Nursing 2010; 23(2):1-7.

[84] Baratta MT, Dorman HJD, Deans SG, Biondi DM and Ruberto G. Chemical composition, antimicrobial and antioxidative activity of laurel, sage, rosemary, oregano and coriander essential oils. J Ess Oil Res 1998; 10: 618-627.

[85] Ratha bai V and Kanimozhi D. Evaluation of antimicrobial activity of Coriandrum sativum. International Journal of Scientific Research and Reviews 2012;1(3): 1-10.

[86] Reddy LH, Jalli RD, Jose B and Gopu S. Evaluation of antibacterial and DPPH radical scavenging activities of the leaf extracts and essential oil of Coriandrum sativum Linn. World Journal of Pharmaceutical research 2012; 1(3): 705-716.

[87] Silva F, Ferreira S, Queiroz JA and Domingues FC. Coriander (Coriandrum sativum L.) essential oil: its antibacterial activity and mode of action evaluated by flow cytometry. J Med Microbiol 2011;60(Pt 10):1479-1486.

[88] De Marco A, Senatore F, Capasso F, Iacobellis NS and Lo Cantore P. Antibacterial activity of Coriandrum sativum L. and Foeniculum vulgare Miller Var. vulgare (Miller) essential oils. J Agric Food Chem 2004; 52(26): 7862-7866.

[89] Kubo I, Fujita K, Kubo A, Nihei K and Ogura T. Antibacterial activity of coriander volatile compounds against Salmonella choleraesuis. J Agric Food Chem 2004; 52(11): 3329-3332.

[90] Rattanachaikunsopon P and Phumkhachorn P. Potential of coriander (Coriandrum sativum m) oil as a natural antimicrobial compound in controlling Campylobacter jejuni in raw meat. Biosci Biotechnol Biochem 2010;74(1):31-35.

[91] Delaquis PJ, Stanich K, Girard B and Mazza G. Antimicrobial activity of individual and mixed fractions of dill, cilantro, coriander and eucalyptus essential oils. Int J Food Microbiol 2002;74(1-2):101-109.

[92] Bogavac M, Karaman M, Janjušević L, Sudji J, Radovanović B, Novaković Z, Simeunović J and Božin B. Alternative treatment of vaginal infections - in vitro antimicrobial and toxic effects of Coriandrum sativum L. and Thymus vulgaris L. essential oils. J Appl Microbiol 2015; 119(3):697-710.

[93] Casetti F, Bartelke S, Biehler K, Augustin M, Schempp CM and Frank U. Antimicrobial activity against bacteria with dermatological relevance and skin tolerance of the essential oil from Coriandrum sativum $\mathrm{L}$. fruits. Phytother Res 2012; 26(3): 420-424.

[94] Gill AO, Delaquis P, Russo P and Holley RA. Evaluation of antilisterial action of cilantro oil on vacuum packed ham. Int J Food Microbiol 2002;73(1):83-92.

[95] 95-Khan DA, Hassan F, Ullah H, Karim S, Baseer A, Abid MA, Ubaidi M, Khan SA and Murtaza G. Antibacterial activity of Phyllantus emblica, Coriandrum sativum, Culinaris medic, Lawsonia alba and Cucumis sativus. Acta Pol Pharm 2013; 70(5):855-859.

[96] Duarte A, Ferreira S, Silva F and Domingues FC. Synergistic activity of coriander oil and conventional antibiotics against Acinetobacter baumannii. Phytomedicine 2012;19(3-4):236-238.

[97] Soares BV, Morais SM, dos Santos Fontenelle RO, Queiroz VA, Vila-Nova NS, Pereira CM, Brito ES, Neto MA, Brito EH, Cavalcante CS, Castelo-Branco DS and Rocha MF. Antifungal activity, toxicity and chemical composition of the essential oil of Coriandrum sativum L fruits. Molecules 2012;17(7):8439-8448. 
[98] Silva F, Ferreira S, Duarte A, Mendonça DI and Domingues FC. Antifungal activity of Coriandrum sativum essential oil, its mode of action against Candida species and potential synergism with amphotericin B. Phytomedicine 2011;19(1):42-47.

[99] Freires Ide A, Murata RM, Furletti VF, Sartoratto A, Alencar SM, Figueira GM, de Oliveira Rodrigues JA, Duarte MC and Rosalen PL. Coriandrum sativum L (Coriander) essential oil: antifungal activity and mode of action on Candida spp., and molecular targets affected in human whole-genome expression. PLoS One 2014;9(6):e99086.

[100] Furletti VF, Teixeira P, Obando-Pereda G, Mardegan RC, Sartoratto A, Figueira GM, Duarte RMT, Rehder VLG, Duarte MCT and Hofling JF. Action of Coriandrum sativum L essential oil upon oral Candida albicans Biofilm formation. Evidence-Based Comp Alter Med 2011; 20(11):1-9.

[101] -Beikert FC, Anastasiadou Z, Fritzen B, Frank U and Augustin M. Topical treatment of tinea pedis using $6 \%$ coriander oil in unguentum leniens: a randomized, controlled, comparative pilot study. Dermatology 2013; 226(1):47-51.

[102] Kim J, Seo SM, Lee SG, Shin SC and Park IK. Nematicidal activity of plant essential oils and components from coriander (Coriandrum sativum), Oriental sweetgum (Liquidambar orientalis), and valerian (Valeriana wallichii) essential oils against pine wood nematode (Bursaphelenchus xylophilus). J Agric Food Chem 2008; 56(16): 7316-7320.

[103] Eguale T, Tilahun G, Debella A, Feleke A and Makonnen E. In vitro and in vivo anthelmintic activity of crude extracts of Coriandrum sativum against Haemonchus contortus. J Ethnopharmacol 2007;110(3):428-433.

[104] Macedo IT, de Oliveira LM, Camurça-Vasconcelos AL, Ribeiro WL, dos Santos JM, de Morais SM, de Paula HC and Bevilaqua CM. In vitro effects of Coriandrum sativum, Tagetes minuta, Alpinia zerumbet and Lantana camara essential oils on Haemonchus contortus. Rev Bras Parasitol Vet 2013; 22(4): 463469.

[105] Rondon FC, Bevilkaqua CM, Accioly MP, Morais SM, Andrade-Junior HF, Machado LK, Cardoso RP, Almeida CA, Queiroz-Junior EM and Rodrigues AC. In vitro effect of Aloe vera, Coriandrum sativum and Ricinus communis fractions on Leishmania infantum and on murine monocytic cells. Vet Parasitol 2011; 178(3-4):235-240.

[106] Khani A and Rahdari T. Chemical composition and insecticidal activity of essential oil from Coriandrum sativum seeds against Tribolium confusum and Callosobruchus maculatus. ISRN Pharm 2012;2012:263517. doi: 10.5402/2012/ 263517.

[107] Benelli G, Flamini G, Fiore G, Cioni PL and Conti B. Larvicidal and repellent activity of the essential oil of Coriandrum sativum L. (Apiaceae) fruits against the filariasis vector Aedes albopictus Skuse (Diptera: Culicidae). Parasitol Res 2013; 112(3): 1155-1161.

[108] Wong PY and Kitts DD. Studies on the dual antioxidant and antibacterial properties of parsley (Petroselinum crispum) and cilantro (Coriandrum sativum) extracts. Food Chem 2006;97:505-515.

[109] Hashim MS, Lincy S, Remya V, Teena M and Anila L. Effect of polyphenolic compounds from Coriandrum sativum on $\mathrm{H}_{2} \mathrm{O}_{2}$-induced oxidative stress in human lymphocytes. Food Chem. 2005;92:653660.

[110] Wangensteen H, Samuelsen AB and Malterud KE. Antioxidant activity in extracts from coriander. Food Chem 2004; 88: 293-297.

[111] Panjwani D, Mishra B and Banji D. Time dependent antioxidant activity of fresh juice of leaves of Coriandrum sativum. International Journal of Pharmaceutical Sciences and Drug Research 2010; 2(1): 63 66.

[112] Anilakumar KR, Nagaraj NS, Santhanam K. Effect of coriander seeds on hexachlorocyclohexane induced lipid peroxidation in rat liver. Nutr Res 2001; 21(11): 1455-62.

[113] Chithra V and Leelamma S. Coriandrum sativum changes the levels of lipid peroxides and activity of antioxidant enzymes in experimental animals. Indian J Biochem Biophys 1999; 36(1):59-61.

[114] Moustafa AH, Ali EM, Moselhey SS, Tousson E and El-Said KS. Effect of coriander on thioacetamideinduced hepatotoxicity in rats. Toxicol Ind Health 2014; 30(7): 621-629.

[115] Dias MI, Barros L, Sousa MJ and Ferreira IC. Comparative study of lipophilic and hydrophilic antioxidants from in vivo and in vitro grown Coriandrum sativum. Plant Foods Hum Nutr 2011; 66(2): 181-186.

[116] Kousar S, Jahan N, Khalil-ur-Rehman and Nosheen S. Antilipidemic activity of Coriandrum sativum. Bioscience Research 2011; 8(1): 8-14.

[117] Joshi SC, Sharma N and Sharma P. Antioxidant and lipid lowering effect of Coriandrum sativum in cholesterol fed rabbits. Int J Pharm Pharm Sci 2012; 4(3):231-234.

[118] La AA, Kumar T, Murthy PB and Pillai KS. Hypolipidemic effect of Coriandrum sativum L. in tritoninduced hyperlipidemic rats. Indian J Exp Biol 2004; 42(9): 909-912. 
[119] Chithra V and Leelamma S. Coriandrum sativum has antioxidant activity. J Nutr Biochem 2009;20(11):901-908.

[120] Dhanapakiam P, Joseph JM, Ramaswamy VK, Moorthi M and Kumar AS. Coriandor seeds have a cholesterollowering action. J Environ Biol 2008;29(1):53-56.

[121] Chithra V and Leelamma S. Hypolipidemic effect of coriander seeds (Coriandrum sativum): mechanism of action. Plant Foods Hum Nutr 1997;51(2):167-172.

[122] Ertas ON, Guler T, Cftc M, Dalklc B and Ylmaz O. The effect of a dietary supplement coriander seeds on the fatty acid composition of breast muscle in Japanese quail. Revue de Médecine Vétérinaire. 2005; 156(10): 514-518.

[123] Patel D, Desai S, Gajaria T, Devkar R and Ramachandran AV. Coriandrum sativum L. seeds extract mitigates lipotoxicity in raw 264.7 cells and prevents atherogenic changes in rats. EXCLI Journal 2013; 12: 313-334.

[124] Nair V, Singh S and Gupta YK. Anti-granuloma activity of Coriandrum sativum in experimental models. J Ayurveda Integr Med 2013; 4(1): 13-18.

[125] Hashemi VH, Ghanadi A and Sharif B. Anti-inflammatory and analgesic effects of Coriandrum sativum L in animal models. J Shahrekord Univ Med Sci 2003; 5(2): 8-15.

[126] Taherian AA, Vafaei AA and Ameri J. Opiate system mediate the antinociceptive effects of Coriandrum sativum in mice. Iranian Journal of Pharmaceutical Research 2012; 11 (2): 679-688.

[127] -Neha Mohan PV, Suganthi V and Gowri S. Evaluation of anti-inflammatory activity in ethanolic extract of Coriandrum sativum L using carrageenan induced paw oedema in albino rats. Der Pharma Chemica 2013; 5(2):139-143.

[128] Nair V, Singh S and Gupta YK. Evaluation of disease modifying activity of Coriandrum sativum in experimental models. Indian J Med Res 2012;135:240-245.

[129] Heidari B, Sajjadi SE and Minaiyan M. Effect of Coriandrum sativum hydroalcoholic extract and its essential oil on acetic acid- induced acute colitis in rats. Avicenna J Phytomed 2015, http://ajp.mums.ac.ir/article_5157_0.html

[130] 130-Jagtap AG, Shirke SS and Phadke AS. A polyherbal formulation compares favorably to prednisolone in experimental models of inflammatory bowel diseases. Reprod Toxicol 2007 ;23(2):182-191.

[131] Wu TT, Tsai CW, Yao HT, Lii CK, Chen HW, Wu YL, Chen PY and Liu KL. Extracts from the aerial part of Coriandrum sativum has anti-inflammatory properties. J Sci Food Agric 2010; 90(11): 1846-1854.

[132] Reuter J, Huyke C, Casetti F, Theek C, Frank U, Augustin M and Schempp C. Anti-inflammatory potential of a lipolotion containing coriander oil in the ultraviolet erythema test. J Dtsch Dermatol Ges 2008;6(10):847-851

[133] Beikert FC, Schönfeld BS, Frank U and Augustin M. Antiinflammatory potential of seven plant extracts in the ultraviolet erythema test. A randomized, placebo-controlled study. Hautarzt 2013; 64(1): 40-46.

[134] Rajeshwari CU and Andallu B. Oxidative stress in NIDDM patients: influence of coriander (Coriandrum sativum) seeds. Research Journal of Pharmaceutical, Biological and Chemical Sciences 2011; 2(1): 31-41.

[135] Waheed A, Miana GA, Ahmad SI and Khan MA. Clinical investigation of hypoglycemic effect of Coriandrum sativum in type-2 (NIDDM) diabetic patients. Pakistan Journal of Pharmacology 2006; 23(1): 7-11.

[136] Naquvi KJ, Ali M and Ahamad J. Antidiabetic activity of aqueous extract of Coriandrum sativum L. fruits in streptozotocin induced rats. Int J Pharm Pharm Sci 2012; 4 ( Suppl 1): 239-240.

[137] 137-Mazhar $\mathbf{J}$ and Mazumder A. Evaluation of antidiabetic activity of methanolic leaf extract of Coriandrum sativum in alloxan induced diabetic rats. Research Journal of Pharmaceutical, Biological and Chemical Sciences 2013; 3(4): 500-507.

[138] 138-Gray AM and Flatt PR. Insulin-releasing and insulin-like activity of the traditional anti-diabetic plant Coriandrum sativum (coriander). Br J Nutr 1999;81(3):203-209.

[139] Patel DK, Desal SN, Devkar RV and Ramachandran AV. Coriandrum sativum L. aqueous extract mitigates high fat diet induced insulin resistance by controlling visceral adiposity. Boletín Latinoamericano y del Caribe de Plantas Medicinales y Aromáticas 2011; 10(2): 127-135.

[140] Eidi M, Eidi A, Saeidi A, Molanaei S, Sadeghipour A, Bahar M and Bahar K. Effect of coriander seed (Coriandrum sativum L.) ethanol extract on insulin release from pancreatic beta cells in streptozotocininduced diabetic rats. Phytother Res 2009; 23(3): 404-406.

[141] Aissaoui A, Zizi S, Israili ZH and Lyoussi B. Hypoglycemic and hypolipidemic effects of Coriandrum sativum L. in Meriones shawi rats. J Ethnopharmacol 2011; 137(1): 652-661.

[142] Brindis F, González-Andrade M, González-Trujano ME, Estrada-Soto S and Villalobos-Molina R. Postprandial glycaemia and inhibition of $\alpha$-glucosidase activity by aqueous extract from Coriandrum sativum. Nat Prod Res 2014; 28(22): 2021-2025. 
[143] Reyes MR, Reyes-Esparza J, Angeles OT and Rodríguez-Fragoso L. Mutagenicity and safety evaluation of water extract of Coriandrum sativum leaves. J Food Sci 2010;75(1):T6-12.

[144] Cortés-Eslava J, Gómez-Arroyo S, Villalobos-Pietrini R and Espinosa-Aguirre JJ. Antimutagenicity of coriander (Coriandrum sativum) juice on the mutagenesis produced by plant metabolites of aromatic amines. Toxicol Lett 2004; 153(2): 283-292.

[145] Nalini N, Sabitha K, Viswanathan P and Menon VP. Influence of spices on the bacterial (enzyme) activity in experimental colon cancer. J Ethnopharmacol. 1998; 62(1): 15-24.

[146] -Chithra V and Leelamma S. Coriandrum sativum -effect on lipid metabolism in 1,2-dimethyl hydrazine induced colon cancer. J Ethnopharmacol 2000; 71(3):457-463.

[147] Tang EL, Rajarajeswaran J, Fung SY and Kanthimathi MS. Antioxidant activity of Coriandrum sativum and protection against DNA damage and cancer cell migration. BMC Complement Altern Med 2013;13:347.

[148] Omez-Flores R, Hernández-Martínez H, Tamez-Guerra P, Tamez-Guerra R, Quintanilla-Licea R, Monreal- Cuevas R and Rodríguez-Padilla C. Antitumor and immunomodulating potential of Coriandrum sativum, Piper nigrum and Cinnamomum zeylanicum. Journal of Natural Products 2010; 3: 54-63.

[149] Rodriguez L, Ramirez M, Badillo M, León-Buitimea A and Reyes-Esparza J. Toxicological evaluation of Coriandrum sativum (Cilantro) using in vivo and in vitro models. The FASEB Journal 2006;20: A645

[150] abeen Q, Bashir S, Lyoussi B and Gilani AH. Coriander fruit exhibits gut modulatory, blood pressure lowering and diuretic activities. J Ethnopharmacol 2009;122(1):123-130.

[151] Medhin DG, Bakos P and Hadházy P. Inhibitory effects of extracts of Lupinus termis and Coriandrum sativum on electrically induced contraction of the rabbit ear artery. Acta Pharm Hung 1986; 56(3): 109113.

[152] Medhin DG, Hadhazy P, Bakos P and Verzar-Petri G. Hypotensive effects of Lupinus termis and Coriandrum sativum in anesthetized rats: preliminary study. Acta Pharmaceutica Hungarica 1986; 56(2): 59-63.

[153] Patel DK, Desai SN, Gandhi HP, Devkar RV and Ramachandran AV. Cardio protective effect of Coriandrum sativum L. on isoproterenol induced myocardial necrosis in rats. Food Chem Toxicol 2012;50(9):3120-3125.

[154] Yaghini J, Shahabooei M, Aslani A, Zadeh MR, Kiani S and Naghsh N. Efficacy of a local-drug delivery gel containing extracts of Quercus brantii and Coriandrum sativum as an adjunct to scaling and root planing in moderate chronic periodontitis patients. J Res Pharm Pract 2014; 3(2): 67-71.

[155] Al-Mofleh IA, Alhaider AA, Mossa JS, Al-Sohaibani MO, Rafatullah S and Qureshi S. Protection of gastric mucosal damage by Coriandrum sativum L. pretreatment in Wistar albino rats. Environ Toxicol Pharmacol 2006; 22(1): 64-69.

[156] Zaidi SF, Muhammad JS, Shahryar S, Usmanghani K, Gilani AH, Jafri W and Sugiyama T. Antiinflammatory and cytoprotective effects of selected Pakistani medicinal plants in Helicobacter pyloriinfected gastric epithelial cells. J Ethnopharmacol 2012; 141(1): 403-410.

[157] Nematy M, Kamgar M, Mohajeri SM, Tabatabaei Zadeh SA, Jomezadeh MR, Akbarieh Hasani O, Kamali N, Vojouhi S, Baghban S, Aghaei A, Soukhtanloo M, Hosseini M, Gholamnezhad Z, Rakhshandeh H, Norouzy A, Esmaily H, Ghayour-Mobarhan M and Patterson M. The effect of hydroalcoholic extract of Coriandrum sativum on rat appetite. Avicenna J Phytomed 2013; 3(1): 91-97.

[158] Farag MFS. Evaluation of radio protective effects of Coriander (Coriandrum sativum L.) in male rats. Arab Journal of Nuclear Science and Applications 2013; 46(1): 240-249.

[159] Sreelatha S, Padma PR and Umadevi M. Protective effects of Coriandrum sativum extracts on carbon tetrachloride-induced hepatotoxicity in rats. Food Chem Toxicol 2009; 47(4): 702-708.

[160] Samojlik I, Lakić N, Mimica-Dukić N, Daković-Svajcer K and Bozin B. Antioxidant and hepatoprotective potential of essential oils of coriander (Coriandrum sativum L.) and caraway (Carum carvi L.) (Apiaceae). J Agric Food Chem 2010;58(15):8848-8853.

[161] 161-Anilakumar KR, Khanum F and Bawa AS. Effect of coriander seed powder (CSP) on 1, 2-dimethyl hydrazine-induced changes in antioxidant enzyme system and lipid peroxide formation in rats. J Diet Suppl 2010;7(1):9-20.

[162] 162-Ikeura H, Kohara K, Li XX, Kobayashi F and Hayata Y. Identification of (E,E)-2,4-undecadienal from coriander (Coriandrum sativum L.) as a highly effective deodorant compound against the offensive odor of porcine large intestine. J Agric Food Chem 2010;58(20):11014-11017.

[163] Aga M, Iwaki K, Ueda Y, Ushio S, Masaki N, Fukuda S, Kimoto T, Ikeda M and Kurimoto M. Preventive effect of Coriandrum sativum (Chinese parsley) on localized lead deposition in ICR mice. J Ethnopharmacol 2001; 77(2-3): 203-208. 
[164] Sharma V, Kansal L, Sharma A, Lodi S and Sharma SH. Ameliorating effect of Coriandrum sativum extracts on hematological and immunological variables in an animal model of lead intoxication. Journal of Pharmacy and Allied Health Sciences 2011; 1: 16-29.

[165] Sharma V, Kansal L and Sharma A. Prophylactic efficacy of Coriandrum sativum (Coriander) on testis of lead-exposed mice. Biol Trace Elem Res 2010; 136(3): 337-354.

[166] Velaga MK, Yallapragada PR, Williams D, Rajanna S and Bettaiya R. Hydroalcoholic seed extract of Coriandrum sativum (Coriander) alleviates lead-induced oxidative stress in different regions of rat brain. Biol Trace Elem Res 2014; 159(1-3): 351-363.

[167] Kansal L, Sharma V, Sharma A, Lodi S and Sharma SH. Protective role of Coriandrum sativum (coriander) extracts against lead nitrate induced oxidative stress and tissue damage in the liver and kidney in male mice. International Journal of Applied Biology and Pharmaceutical Technology 2011; 2(3): 65-83.

[168] Aissaoui A, El-Hilaly J, Israili ZH and Lyoussi B. Acute diuretic effect of continuous intravenous infusion of an aqueous extract of Coriandrum sativum L. in anesthetized rats. J Ethnopharmacol 2008; 115(1): 8995.

[169] Hwang E, Lee DG, Park SH, Oh MS and Kim SY. Coriander leaf extract exerts antioxidant activity and protects against UVB-induced photoaging of skin by regulation of procollagen type I and MMP-1 expression. J Med Food 2014; 17(9): 985-995.

[170] Park G, Kim HG, Lim S, Lee W, Sim Y and Oh MS. Coriander alleviates 2,4-dinitrochlorobenzeneinduced contact dermatitis-like skin lesions in mice. J Med Food 2014;17(8):862-868.

[171] Park G, Kim HG, Kim YO, Park SH, Kim SY and Oh MS. Coriandrum sativum L. protects human keratinocytes from oxidative stress by regulating oxidative defense systems. Skin Pharmacol Physiol 2012; 25(2): 93-99.

[172] Al-Said MS, Al-Khamis KI, Islam MW, Parmar NS, Tariq M and Ageel AM. Post-coital antifertility activity of the seeds of Coriandrum sativum in rats. J Ethnopharmacol 1987; 21(2): 165-173.

[173] Özbek H, Him A and Turkozu D. The levels of lethal dose and anti-inflammatory effect of Coriandrum sativum L. essential oil extract. Ege J Med 2006; 45(3): 163-167. 